\title{
Unenlagiid theropods: are they members of the Dromaeosauridae (Theropoda, Maniraptora)?
}

\author{
FEDERICO L. AGNOLIN ${ }^{1,2}$ and FERNANDO E. NOVAS ${ }^{1}$ \\ ${ }^{1}$ Laboratorio de Anatomía Comparada y Evolución de los Vertebrados \\ Museo Argentino de Ciencias Naturales "Bernardino Rivadavia" \\ Ángel Gallardo, 470 (1405BDB), Buenos Aires, Argentina \\ ${ }^{2}$ Fundación de Historia Natural "Félix de Azara", Departamento de Ciencias Naturales y Antropología \\ CEBBAD, Universidad Maimónides, Valentín Virasoro 732 (1405BDB), Buenos Aires, Argentina
}

Manuscript received on November 9, 2009; accepted for publication on June 21, 2010

\begin{abstract}
In the present paper we analyze the phylogenetic position of the derived Gondwanan theropod clade Unenlagiidae. Although this group has been frequently considered as deeply nested within Deinonychosauria and Dromaeosauridae, most of the features supporting this interpretation are conflictive, at least. Modification of integrative databases, such as that recently published by Hu et al. (2009), produces significant changes in the topological distribution of taxa within Deinonychosauria, depicting unenlagiids outside this clade. Our analysis retrieves, in contrast, a monophyletic Avialae formed by Unenlagiidae plus Aves.
\end{abstract}

Key words: Gondwana, Deinonychosauria, Dromaeosauridae, Unenlagiidae, Avialae.

\section{INTRODUCTION}

Until recently, the deinonychosaurian fossil record has been geographically restricted to the Northern Hemisphere (Norell and Makovicky 2004), but recent discoveries demonstrated that they were also present and highly diversified in the Southern landmasses, suggesting that an important adaptive radiation took place in Gondwana during the Cretaceous.

Gondwanan dromaeosaurids have been documented from Turonian through Maastrichtian beds of Argentina (Makovicky et al. 2005, Novas and Puerta 1997, Calvo et al. 2004, Novas and Pol 2005, Novas et al. 2009), and also probably from the Latest Cretaceous of Madagascar (Forster et al. 1998, Makovicky et al. 2005).

The term Unenlagiidae was coined by Bonaparte (1999) to include the South American Unenlagia and the Malagasy Rahonavis, as well as the poorly known Early Cretaceous Australian genus Timimus (Rich

Proceedings of the Third Gondwanan Dinosaur Symposium

Correspondence to: Federico L. Agnolin

E-mail: fedeagnolin@yahoo.com.ar 
and Vickers-Rich 1993). Later, Makovicky et al. (2005) coined the subfamily term Unenlagiinae, to fit this clade within the family Dromaeosauridae.

In the current usage, the subfamily Unenlagiinae is applied to the clade formed by Unenlagia, Neuquenraptor, Buitreraptor, Austroraptor, and probably Rahonavis (Makovicky et al. 2005, Xu et al. 2008, Hu et al. 2009). It is important to mention here that Makovicky et al. (2005) interpreted Neuquenraptor argentinus (Novas and Pol 2005) as junior synonym of Unenlagia comahuensis.

In its original description, Unenlagia was interpreted as closer to birds than the remaining dromaeosaurids (Novas and Puerta 1997), a point of view that was followed by some authors (Forster et al. 1998, Xu et al. 1999, Rauhut 2003, Novas 2004). Nevertheless, most researchers concluded that Unenlagia and its kin were deeply nested within Dromaeosauridae and Deinonychosauria (Norell and Makovicky 1999, Novas and Pol 2005, Makovicky et al. 2005, Longrich and Currie 2008, Xu et al. 2008, Novas et al. 2009, $\mathrm{Hu}$ et al. 2009). In summary, the clade Unenlagiinae is currently considered as the sister group of the remaining dromaeosaurids (Makovicky et al. 2005, Senter 2007; Fig. 1A).

The goal of the present paper is to make a brief overview about deinonychosaurian and dromaeosaurid synapomorphic features that have been cited for unenlagiids with the aim to evaluate the higherlevel phylogenetic relationships of this family of theropods.

Most previous phylogenetic analyses were based on the Theropod Working Group matrix (TwiG), which corresponds to the most integrative analysis of coelurosaurian theropods currently available (Norell et al. 2001, Hu et al. 2009; see also Xu et al. 2008). We reanalyze the most recent version of this data matrix with the aim to corroborate the phylogenetic position of Unenlagiidae. We offer an updated codification of derived features present in unenlagiids, but also review some characteristics that were originally interpreted as diagnostic of Deinonychosauria and Dromaeosauridae. After the recoding of several traits in the matrix by $\mathrm{Hu}$ et al. (2009), some changes in the tree topology become apparent, and they will be considered in the following pages (see Appendix IV).

\section{AbBreviations}

HMN - Museum für Naturkunde, Berlin, Germany.

IVPP V - The Institute of Vertebrate Paleontology and Paleoanthropology, Beijin, China.

MCF PVPH - Museo Carmen Funes, Plaza Huincul, Neuquén, Argentina.

MML - Museo Municipal de Lamarque, Lamarque, Río Negro, Argentina.

MPCA - Museo Provincial Carlos Ameghino, Cippolletti, Río Negro, Argentina.

\section{MATERIALS AND METHODS}

With the aim to discuss the phylogenetic relationships of unenlagiids with respect to the remaining paravians, we performed a phylogenetic analysis using the most recent version of the TwiG, presented by $\mathrm{Hu}$ et al. (2009). We have partially modified this dataset, consisting of 88 taxa scored for 366 characters (see Appendices I-II). Definitions of characters 1 through 363 follow Hu et al. (2009); characters 364 through 365 have been added from Novas et al. (2009); character 366 is from Gianechini et al. (2009). We have modified character 199 with the addition of a new character-state (2). In addition, the taxon list used by 

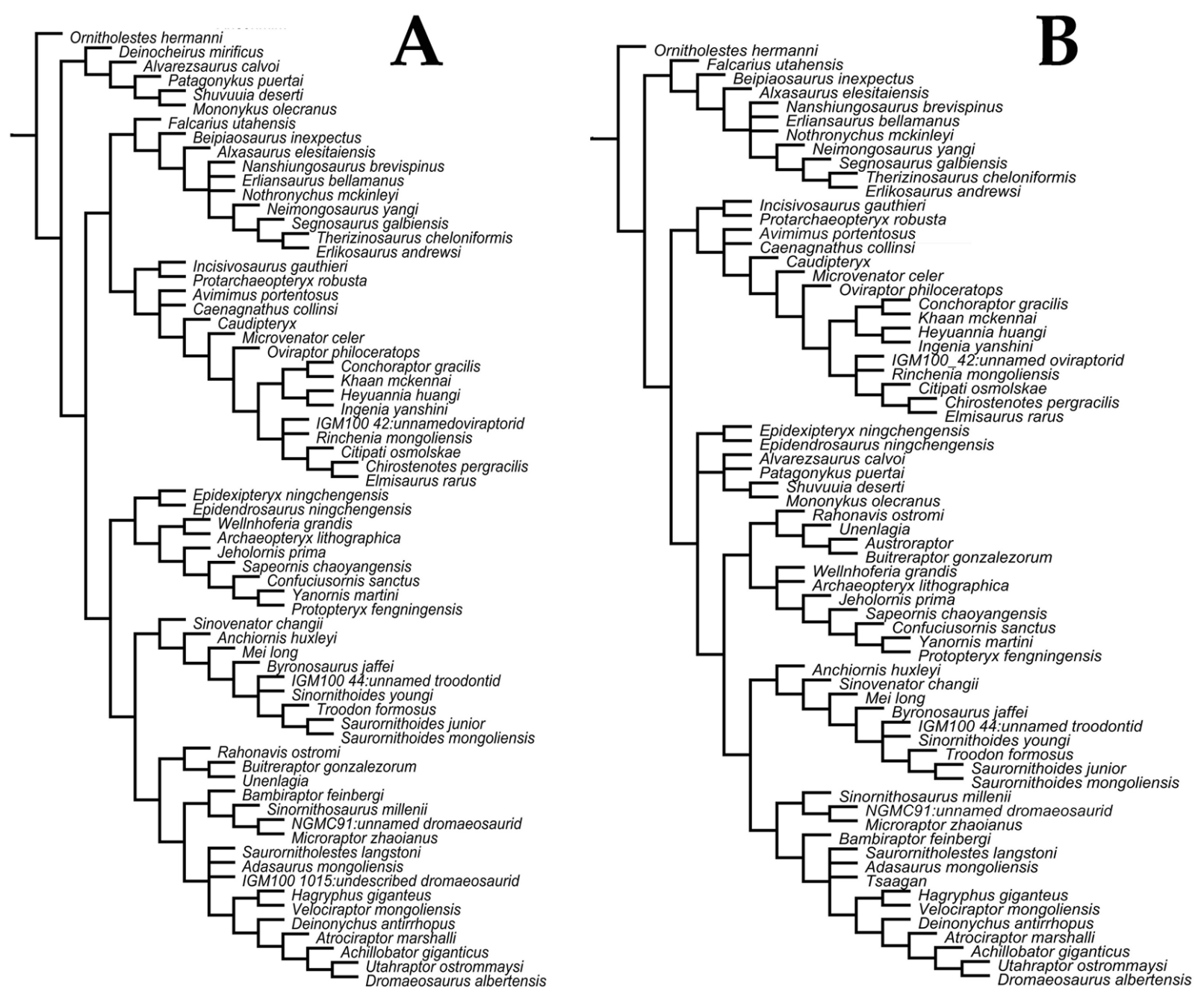

Fig. 1 - Alternative interpretations about the phylogenetic relationships of Unenlagiidae. A, phylogeny proposed by Hu et al. (2009), depicting unenlagiids as nested within Deinonychosauria and Dromaeosauridae; B, present analysis, depicting unenlagiids as the sister group of Aves.

$\mathrm{Hu}$ et al. (2009) has been increased with the inclusion of the newly described unenlagiid theropod Austroraptor cabazai (Novas et al. 2009). As proposed by Makovicky et al. (2005), we consider Neuquenraptor argentinus Novas and Pol 2005, as a junior synonym of Unenlagia comahuensis Novas and Puerta 1997.

For the present paper we opt for the use of the original family name Unenlagiidae Bonaparte 1999 (instead of Unenlagiinae; sensu Makovicky et al. 2005), to emphasize the distinctiveness of this theropod group. We follow the nomenclature and taxonomy employed by Norell et al. (2001) and Chiappe (2001) for non-avian coelurosaurs and Aves, respectively.

Phylogenetic analysis was performed using TNT 1.0 (Goloboff et al. 2003). All characters were equally weighted and treated as unordered. A heuristic search was performed with 10,000 random addition sequence replicates to find the most parsimonious trees for the data matrix. Tree bisection and reconnection (TBR) was utilized as the branch-swapping algorithm for the heuristic search. Heuristic searches 
were performed on 1,000 pseudoreplicate datasets, with 10 random addition sequence replicates for each search. The maximum number of trees saved for each random addition sequence replicate was set to 100 . Ratchet searches were performed on 2,000 pseudoreplicate datasets. The phylogenetic analysis resulted in the recovery of 145 Most Parsimonious Trees (MPTs), which yield a Strict Consensus Tree of 1440 steps, with a consistency index of 0.31 and a retention index of 0.71 (Fig. 1B).

\section{CHARACTER ANALYSIS}

We discuss below all the traits that have been considered as synapomorphic of Deinonychosauria and/or Dromaeosauridae by previous authors (e.g. Xu et al. 2000, 2008, Makovicky et al. 2005, Novas and Pol 2005, Norell et al. 2001, 2006, Turner et al. 2007a, b, Novas et al. 2009). Characters whose definitions were taken from $\mathrm{Hu}$ et al. (2009) are preceded with the letter H; characters taken from Xu et al. (2008) are preceded with the letter $\mathrm{X}$.

\section{REVIEW OF PUTATIVE SyNAPOMORPHIES OF DEINONYCHOSAURIA}

1 - Lacrimal with anterodorsal process much longer than posterior process (ch. H40). A welldeveloped anterodorsal process of the lacrimal is present in most deinonychosaurians, and was considered as diagnostic for this group (Novas et al. 2009, Hu et al. 2009). In fact, an elongate anterodorsal process of the lacrimal, rivaling the size of the ventral process is a trait seen in most dromaeosaurids, and appears to be especially long in derived troodontids (Makovicky and Norell 2004). Among unenlagiids, the lacrimal is preserved in Austroraptor, in which the anterodorsal process is slightly curved ventrally, being subequal in length to the ventral process. Notably, Austroraptor resembles troodontids, although in the latter ones the anterodorsal process is even larger than the ventral one (e.g. Byronosaurus, Saurornithoides; Barsbold 1974, Makovicky et al. 2003). The presence of a lacrimal with an anterodorsal process much longer than the posterior process is, however, not unique for deinoychosaurians, as it is also present in Archaeopteryx (Novas et al. 2009) as well as in several basal birds, including Jeholornis and most Enantiornithes (Chiappe and Walker 2002). Unfortunately, the preserved specimens of Confusiusornis (Chiappe et al. 1999) and Zhongornis (Gao et al. 2008) precludes us to known if such morphology of lacrimal also applies to these early birds.

In summary, the present analysis supports that the presence of a large anterodorsal process on the lacrimal is diagnostic of the clade Paraves.

2 - Nutrient foramina on external surface of the dentary lie within a deep groove (ch. H72). The presence of a well-delimited, narrow, and deep longitudinal groove along the alveolar margin of the dentary, carrying a series of small nutrient foramina was previously considered as diagnostic of Troodontidae (Sues 1977, Currie 1987). More recently, Xu et al. (2008) have suggested that this condition may be diagnostic of Deinonychosauria, because it is also present in members of the clade Microraptoria (e.g. Microraptor, Sinornithosaurus; Xu et al. 1999, 2000, 2003), as well as in unenlagiids, (Buitreraptor, Austroraptor, Makovicky et al. 2005, Novas et al. 2009; Fig. 2). Moreover, its presence in the latter taxa prompted Novas et al. (2009) to suggest that it may constitute a diagnostic feature of Unenlagiidae. However, the presence of a similar groove among early avian taxa (e.g., Archaeopteryx, Enantiornithes, 


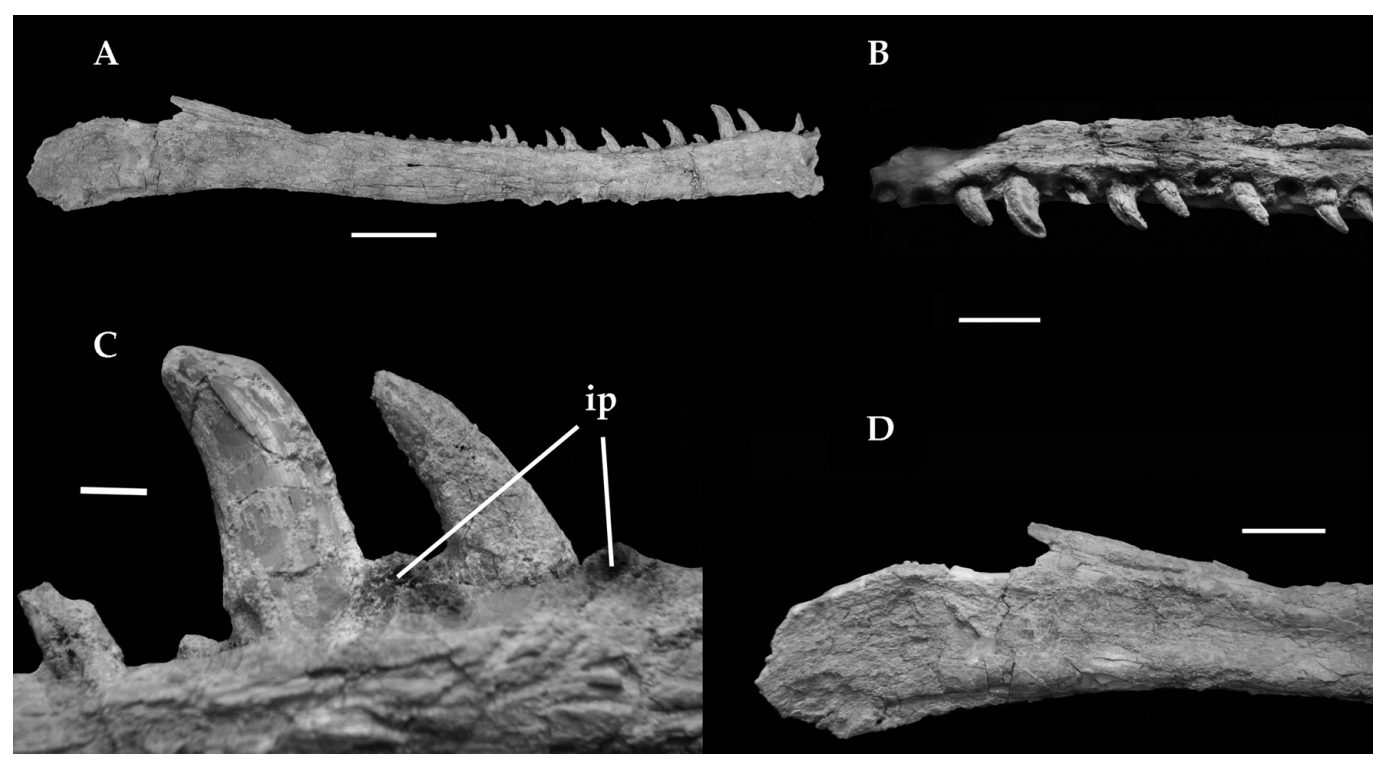

Fig. 2 - Right dentary of Austroraptor cabazai (MML, 195; holotype), A, lateral view of dentary; B, dorsal view of dentary showing anterior alveoli; $\mathbf{C}$, medial view of dentary showing detail of interdental plates; $\mathbf{D}$, posterior end of dentary in lateral view. Scale bar $5 \mathrm{~cm}$. Abbreviations: ip, interdental plates.

Ichthyornis; Elzanowski and Wellnhofer 1996, Chiappe and Walker 2002) suggest that this condition may be more widespread than previously thought.

The recoding of this character in the present analysis weakens its status as a deinonychosaurian synapomorphy. Moreover, in the context of the present analysis, this feature is not retrieved as diagnostic of any coelurosaurian clade.

3 - Anterior dentary teeth smaller, more numerous, and more closely appressed than those of the middle tooth row (ch. H90). This condition was originally considered as diagnostic of Troodontidae (Sues 1977). Moreover, Sues (1977) indicated that anterior dentary teeth not only were closely appressed, but also lacked separated alveoli, as all the anterior teeth are set in an open groove. Recently, and based on the discoveries of Microraptor and Sinornithosaurus, Xu et al. (2008) suggested that this condition may be better considered as diagnostic of Deinonychosauria. Preserved portions of the dentary in Austroraptor and Buitreraptor clearly indicate that in the latter two taxa the dentary teeth are inserted into separate alveoli, and that they are similar in size to posterior teeth (Gianechini et al. 2009; Fig. 2B).

4 - Roots of dentary and maxillary teeth mediolaterally compressed (ch. H228). Hu et al. (2009) considered this morphology as diagnostic of Deinonychosauria. However, such a condition is difficult to quantify in basal deinonychosaurians (e.g. Mei, Sinovenator, Microraptor, Graciliraptor) and have been consequently coded by $\mathrm{Hu}$ et al. (2009) as indeterminate in their data matrix. However, preserved remains in Anchiornis, Mei, Sinovenator, and Microraptor suggest that the roots of dentary and maxillary teeth may be subcircular in cross-section (Xu 2002, Xu and Norell 2004, Hu et al. 2009), as also occurs in basal birds (e.g. Archaeopteryx, Enantiornithes; Elzanowski 2002, Chiappe and Walker 2002). Within unenlagiids, the morphology of tooth roots is variable: in Buitreraptor the roots are transversely compressed, but in Austroraptor the roots are subcircular in cross section (Gianechini et al. 2009). 
In conclusion, the degree of compression of tooth roots is a trait with an ambiguous distribution among Paraves and, consequently, it is not phylogenetically informative in the context of the present cladistic analysis.

5 - Dentaries lack distinct interdental plates (ch. H90). (Fig. 2C). Currie (1995) has noted that fused interdental plates in dentary and maxillary bones constitutes a diagnostic character for Dromaeosauridae, and that the absence of such plates in Troodontidae represents an apomorphic condition of this theropod group. Later, Makovicky et al. (2005) emphasized on the difficulty to discern between the absence or fusion of dental plates in paravian theropods, and suggested that both conditions may be treated as a single one. They concluded that both refer to the absence of clearly defined interdental plates. Following this proposal, $\mathrm{Xu}$ et al. (2008) considered the absence of distinct interdental plates as a derived condition characteristic of Deinonychosauria. Among Unenlagiidae, the dentary is known in Buitreraptor and Austroraptor. In Buitreraptor the dentaries are still embeded in matrix, so the morphology of interdental plates remains unknown. On the other hand, in Austroraptor the dentaries still preserve clear and well-separated interdental plates in the rostral portion of the bone, at least.

These unfused plates are subtriangular in shape, being similar to those observed in Archaeopteryx (Elzanowski and Wellnhofer 1996). In addition, in most basal birds, including Sapeornis, Jeholornis, Confusiusornis, and ornithothoracines, the interdental plates are absent (Chiappe et al. 1999, Zhou and Zhang 2003a, b).

In the present analysis, the presence of distinct interdental plates is considered as an ambiguous synapomorphic trait of the clade formed by Aves + Unenlagiidae (i.e. Avialae).

6 - Splenial exposed as a broad triangle between dentary and angular, on lateral surface of mandible (ch. H76). Currie (1995) proposed a widely exposed splenial subtriangular in shape as diagnostic of Dromaeosauridae, a criterion followed by subsequent authors (Makovicky et al. 2005, Xu et al. 2008, $\mathrm{Hu}$ et al. 2009). Although no single splenial nor angular is completely known in unenlagiids, the preserved portion of the dentary in Austroraptor suggests that the splenial was not exposed in lateral view (Fig. 2D). In fact, in troodontids (e.g. Byronosaurus, Saurornithoides; Barsbold 1974, Makovicky et al. 2003) and dromaeosaurids (e.g. Dromaeosaurus, Sinornithosaurus; Currie 1995, Xu and Wu 2001) the caudoventral process of the dentary is reduced and shows an extensive oblique and posterodorsally oriented articular surface for the splenial, a derived condition unknown in remaining theropods, including birds. In contrast, in Austroraptor the caudal end of the dentary is dorsoventrally deep and the ventral margin curves downwards. This morphology suggests that the splenial was hidden in lateral view (Fig. 2D). In the same way, although the jaws of Buitreraptor are caudally damaged, the splenial appears to lack a lateral exposure, as can be seen in the preserved portion of this bone.

7 - Ilium with antitrochanter posterior to acetabulum prominent (ch. H157). Xu et al. (2002) considered this character as diagnostic of Deinonychosauria. However, a similarly developed antitrochanter is also widely present in basal birds. In contrast with previous proposals (Makovicky et al. 2005, $\mathrm{Xu}$ et al. 2008), an iliac antitrochanter is observed in Archaeopteryx (HMN 1880; Fig. 3B). In addition, a reduced antitrochanter is still present in Confusiusornis and Rahonavis (Chiappe et al. 1999, Novas 2004), whereas it is totally absent in Sapeornis (Zhou and Zhang 2003b). In the unenlagiids Unenlagia 


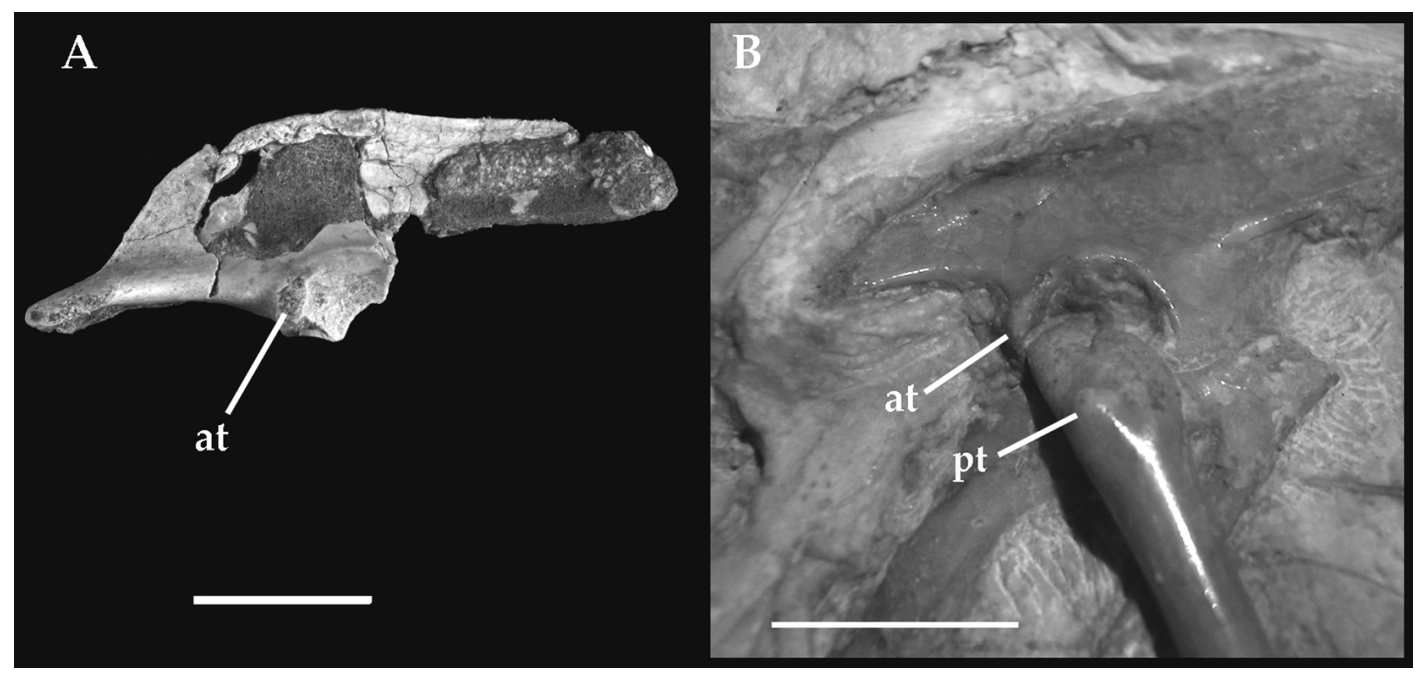

Fig. 3 - Right pelvic girdle of: A, Buitreraptor gonzalezorum (MPCA, 245; holotype); B, Archaeopteryx lithographica (HMN, 1880). Scale bar $1 \mathrm{~cm}$. Abbreviations: at, antitrochanter; pt, posterior trochanter of femur.

and Buitreraptor the antitrochanter is present, but only represented by a slightly raised, craniolaterally oriented surface, which lacks well-defined perimeters (Novas 2004; Fig. 3). This condition resembles the one present in Archaeopteryx.

In this way, the recent analysis by $\mathrm{Hu}$ et al. (2009) considers the presence of a well-developed antitrochanter forming a "hood" over the femoral head as a widespread trait among paravians and, consequently, excludes it from the diagnosis of Deinonychosauria.

8 - Humerus with anterior surface of deltopectoral crest with a distinct muscle scar near the lateral edge along distal end of crest for insertion of biceps muscle (ch. H141). Makovicky et al. (2005) and $\mathrm{Xu}$ et al. (2008) suggested this peculiar condition as diagnostic of Deinonychosauria. In fact, in $\mathrm{Ar}$ chaeopteryx and the remaining birds, there are no signs of a prominent depression for the biceps muscle at the distal end of the deltopectoral crest. On the other hand, in Buitreraptor and Unenlagia there exists a prominent depression bounded by a ridge that defines such biceps insertion (Makovicky et al. 2005), as it occurs in dromaeosaurids. In Austroraptor the humerus is damaged and that the condition of the crest remains uncertain.

This character is retrieved as one of the derived traits that are shared by Unenlagiidae and Deinonychosauria, with the exclusion of Aves.

9 - Ulna with a thick ridge along the anterior margin of the proximal third of the shaft (ch. X257). $\mathrm{Xu}$ et al. (2008) considered this feature as apomorphic of Deinonychosauria. In fact, the presence of such ridge may be corroborated in both Buitreraptor and Rahonavis. In birds, including Archaeopteryx and Enantiornithes, the anterior margin of the ulna is nearly flat (Wellnhofer 1992, Chiappe and Walker 2002).

This character is retrieved as one of the derived traits that are shared by Unenlagiidae and Deinonychosauria, with the exclusion of Aves.

10 - Ulna with little anteroposterior flattening, and with its distal end having a transverse width to anteroposterior length ratio significantly less than 2 (ch. X262). Xu et al. (2008) indicated this feature 
as a synapomorphic trait of Deinonychosauria. Among unenlagiids, the ulna is known in Buitreraptor and Rahonavis. In Buitreraptor this bone is partially preserved, with the distal end damaged. However, the available portion of the ulnar shaft indicates that this genus probably retained the plesiomorphic condition of little anteroposterior compression in the distal end, a morphology that is different from that of Deinonychosauria. The incomplete nature of the ulna in Buitreraptor precludes us to identify with certainty its condition and, in consequence, it is coded as a question mark. Besides, the ulna of Rahonavis does not exhibit an anteroposteriorly compressed distal end (Xu et al. 2008), thus constituting a derived condition shared with most avialans.

In consequence, although the anteroposterior flattening of the ulna may be considered as diagnostic of Deinonychosauria, this condition appears to be absent in known Unenlagiidae.

11 - Femur with posterior trochanter distinctly raised from shaft, mound-like (ch. H183). First considered as diagnostic of Coelurosauria by Gauthier (1986), this condition was suggested as apomorphic of Deinonychosauria by Hu et al. (2009), and it can be clearly observed in the preserved specimens of Buitreraptor and Unenlagia (Novas and Pol 2005, Makovicky et al. 2005). However, a mound-like posterior trochanter is also present in basal birds, including Archaeopteryx (Fig. 3B), Wellnhoferia, and Enantiornithes (Elzanowski 2002, Chiappe and Walker 2002).

In summary, the presence of a mound-like posterior trochanter is retrived in the present analysis as diagnostic of the node Paraves.

12 - Subarctometatarsalian metatarsus (ch. X203). The subarctometatarsalian metatarsus typically shows the proximal shaft of metatarsal III constricted and much narrower than either metatarsals II or IV, but still being exposed along most of the metapodial in anterior and posterior surfaces (Xu et al. 2008; character 203; characters 200 and 358 herein). This trait was suggested as diagnostic of Deinonychosauria by Novas and Pol (2005) and Xu et al. (2008). However, within deinonychosaurians (sensu Hu et al. 2009) this condition is restricted to microraptorian dromaeosaurids (e.g. Sinornithosaurus, Microraptor; $\mathrm{Xu}$ et al. 1999, 2000), unenlagiids (e.g. Unenlagia, Buitreraptor; Novas and Pol 2005, Makovicky et al. 2005; Fig. 4), and basal troodontids (e.g. Sinovenator, Anchiornis; Xu et al. 2002, 2008). Moreover, a similar metatarsal condition is also present in Archaeopteryx and Jeholornis (Zhou and Zhang 2003a, Novas and Pol 2005, Makovicky et al. 2005, Xu et al. 2008; Fig. 4). Although modified by fusion, a subarctometatarsalian metatarsus appears to be present also in a wide variety of Enantiornithes and other basal birds, such as Zhongornis, Zhongjianornis, and probably confusiusornithids (Chiappe and Walker 2002, Gao et al. 2008, Zhou and Zhang Zhiheng Li 2009). Thus, this condition appears to be more widespread than previously thought.

More recently, $\mathrm{Hu}$ et al. (2009) have considered that the subarctometatarsalian metatarsus may be a combination of two different characters: pinching of metatarsal III (ch. H200), and contact between metatarsals II and IV (ch. H358). In any case, Hu et al. (2009) did not consider any of these traits as diagnostic of Deinonychosauria, a result that is in agreement with the present analysis.

13 - Large, longitudinal flange along caudal face of metatarsal IV (ch. H333). This trait, once proposed as diagnostic of Dromaeosauridae (Xu et al. 2002), was suggested by Novas and Pol (2005) as synapomorphic of Deinonychosauria. These authors indicated the presence of such a flange along the 


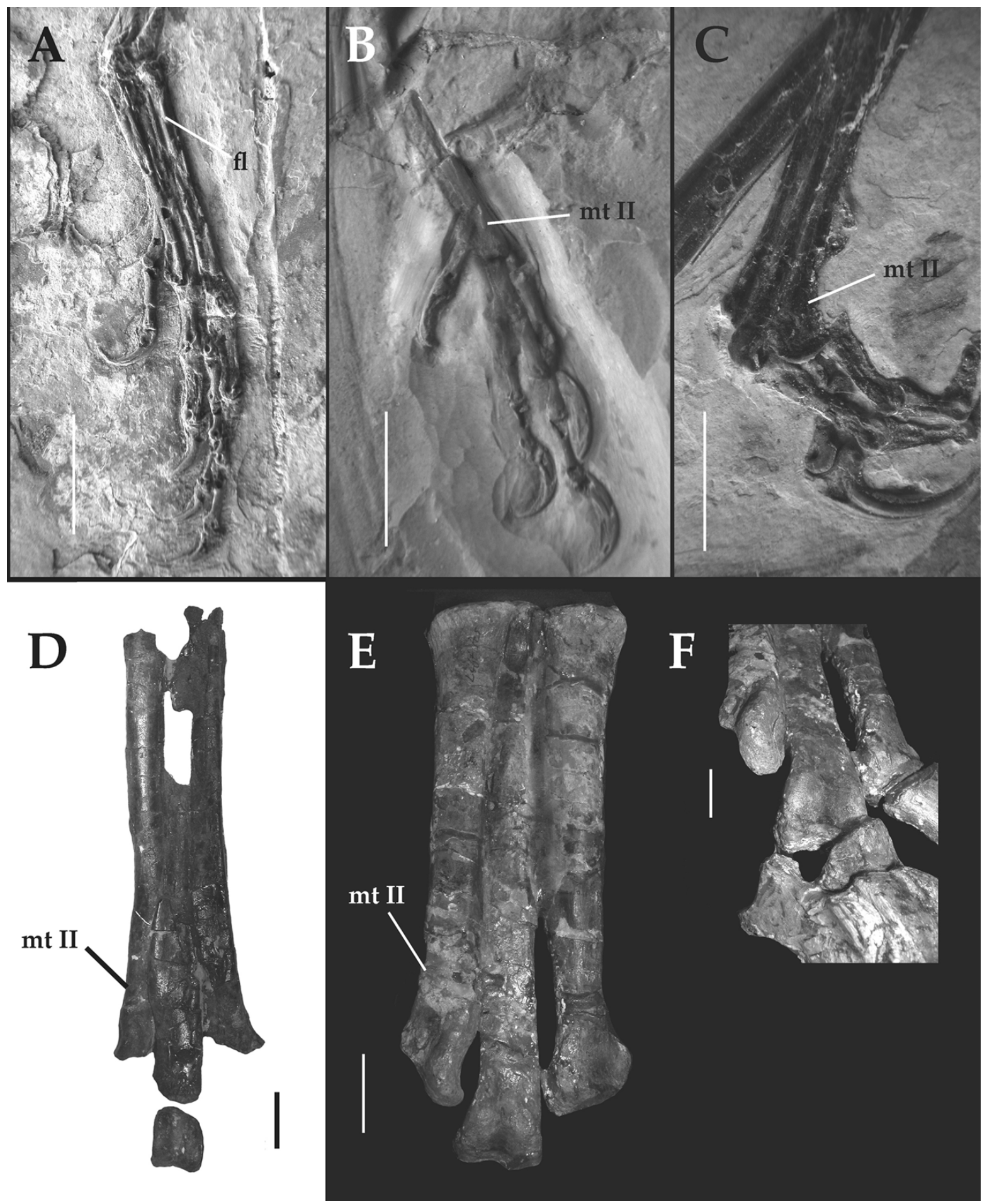

Fig. 4 - Metatarsus of: A, Jeholornis prima (IVPP V 13350) right metatarsus in posterior view; B, Archaeopteryx lithographica (HMN, 1880) left metatarsus in lateral view; C, Microraptor gui (IVPP V 13320) distal end of left metatarsus in anterior view; D, Unenlagia comahuensis (=Neuquenraptor argentinus Novas and Pol 2005; MCF PVPH, 77; holotype) distal end of left metatarsus in anterior view; E-F, Deinonychus antirrhopus (MCZ 4371) left metatarsus in: E, anterior view; F, distal view. Scale bar $2 \mathrm{~cm}$. Abbreviations: 1f, posterior longitudinal flange of metatarsal IV; mt, metatarsal; I, II, III, metatarsal number. 
posterolateral face of metatarsal IV in Unenlagia (= Neuquenraptor), as well as some basal paravians, including Sinovenator, Microraptor, Sinornithosaurus, and Sinornithoides. The same condition has been reported for Buitreraptor and Rahonavis (Forster et al. 1998, Makovicky et al. 2005; Fig. 4). In addition, Archaeopteryx (HMN 1880, Paul 2002; Fig. 4) and Jeholornis (IVPP-V13350; Fig. 4) exhibit the same trait. Unfortunately, in most of the remaining basal birds the morphology of the plantar surface of the metatarsals cannot be properly observed due to defficient preservation of available specimens. However, in Enantiornithes, a similar ridge is described on well preserved tarsometatarsi (Chiappe 1993), suggesting that this condition may be widespread among basal Avialae.

In the present analysis, the presence of a caudal flange along metatarsal IV is considered diagnostic of Paraves.

14 - Metatarsal III distally ginglymous (ch. H199). The presence of a well-developed ginglymoid distal end of metatarsal III is an apomorphic condition that was firstly suggested by Gauthier (1986) as diagnostic of Deinonychosauria, an interpretation that was followed by most recent authors. In fact, in typical dromaeosaurids, such as Velociraptor and Deinonychus, the ginglymoid is clearly seen in posterior and anterior views, and is well extended proximally when viewed anteriorly (Norell and Makovicky 2004; Fig. 4). In addition, in the dromaeosaurid Deinonychus, for example, the ginglymous distal articulation is proximally delimited by a transverse osseous ridge (Ostrom 1969; Fig. 4). In microraptorians (e.g., Microraptor, Graciliraptor, Sinornithosaurus; Xu 2002) the distal ginglymoid is poorly developed, and no excavation of its distal trochlea nor a proximal transverse ridge are evident in anterior view (Hwang et al. 2002). The latter condition is also present in Buitreraptor and Rahonavis, in which the ginglymous is poorly developed, nearly lacking an anterior excavation (Forster et al. 1998, Novas and Pol 2005, Makovicky et al. 2005). This morphology is very similar to that present in the basal birds Jeholornis and Archaeopteryx, as noted by previous authors (Mayr et al. 2005, Novas and Pol 2005, Xu et al. 2008). In most derived Avialae, including Confusiusornis, Ichthyornis, Baptornis, and Neornithes, the distal end of metatarsal III conforms a widely ginglymoid distal trochlea, a condition reminiscent to that seen in typical dromaeosaurids (Martin and Tate 1976, Chiappe et al. 1999, Clarke 2004).

To character 202 we have added a new character-state (state 2), "poorly developed ginglymous, weakly extended proximally", a state not recognized previously (e.g., Hu et al. 2009). Thus, in the present analysis, the presence of a poorly excavated and weakly extended ginglymoid is better interpreted as a paravian feature.

15 - Pedal phalanx II-2 with transversely wide posteroventral lip (ch. H322). Hu et al. (2009) considered the presence of a wide posteroventral lip at the base of phalanx II-2 as diagnostic of Deinonychosauria. However, this condition seems to be absent in Unenlagiidae, in which the posteroventral heel of pedal phalanx II-2 is transverselly narrow, and medially offset, as can be observed in Rahonavis, Unenlagia, Buitreraptor, and Austroraptor (Novas and Pol 2005, Makovicky et al. 2005, Novas et al. 2009).

In summary, although the presence of a wide posteroventral heel or lip in pedal phalanx II-2 is here considered as diagnostic of Deinonychosauria, this condition is absent in Unenlagiidae.

16 - Pedal phalanx II-2 with dorsal extension of distal condyles (ch. H323). Hu et al. (2009) considered the distal condyles of pedal phalanx II-2 dorsally displaced as a diagnostic trait of Deinonychosauria. In 
fact, the dorsally extended condyles of this phalanx are related to the hyperextensible pedal second toe and its corresponding sickle-like claw, a condition traditionally regarded as diagnostic of Deinonychosauria (Gauthier 1986). This derived morphology is present in most troodontids and dromaeosaurids, including Rahonavis, Unenlagia, Buitreraptor, and Austroraptor (Forster et al. 1998, Makovicky et al. 2005, Novas et al. 2009). However, dorsally extended condyles on distal end of phalanx II-2 have been also reported for a wide variety of basal birds, including Archaeopteryx, Jeholornis, Sapeornis, Confusiusornis, and Enantiornithes (Chiappe et al. 1999, Sereno 2000, Paul 2002, Zhou and Zhang 2003a, b).

In this way, the presence of pedal phalanx II-2 with condyles dorsally displaced has a wider distribution among paravians than previously thought.

17 - Trenchant claw on digit II (ch. H201). A large and trenchant ungual on pedal digit II was mentioned for the first time as diagnostic of Deinonychosauria by Gauthier (1986), and accepted as such by most recent authors (e.g., Hu et al. 2009). However, recent discoveries demonstrated that this trenchant ungual is present also in some basal avialans, including Archaeopteryx and Jeholornis (Paul 2002, Zhou and Zhang 2003a, b, Mayr et al. 2005, Xu and Zhang 2005). In this context, the presence of an enlarged ungual on digit II was considered as synapomorphic of Paraves by Xu and Zhang (2005), an interpretation that is accepted here. Although the morphology of phalanges of digit II is not identical in basal birds and deinonychosaurians, the ungual phalanx in both clades is more curved and larger than the remaining phalanges of the foot.

Some authors suggested that the development of a raptorial ungual on pedal digit II was convergently developed in Troodontidae, Dromaeosauridae, and Rahonavis (Forster et al. 1998). Under the present phylogeny, a large ungual on pedal digit II was almost probably acquired early in paravian evolution and was secondarily lost in birds more derived than Jeholornis.

There are some additional traits cited by several authors as diagnostic of Deinonychosauria that cannot be checked among unenlagiids, due to defficient preservation. These traits mostly refer to skull anatomy and include: well developed palatal flange on pterygoid, tetrarradiate palatine, presence of a foramen on the lateral surface of the surangular rostral to the mandibular articulation, coronoid reduced to a thin splint, and manual phalanx III-3 subequal in length to the combined lengths of phalanges III-1 and III-2 (Currie 1995, Makovicky et al. 2005, Currie and Varricchio 2004, Xu et al. 2000, 2008, Novas et al. 2009, Hu et al. 2009).

\section{ReView of Putative Synapomorphies of Dromaeosauridae}

Several features suggested as diagnostic of Dromaeosauridae by previous authors are proven to be conflictive or more widely distributed than previously thought. These traits are the following:

19 - Maxillary fenestra represented by a small and dorsally displaced opening (ch. H240). Turner et al. (2007b) indicated that a dorsally located maxillary fenestra is diagnostic of Dromaeosauridae. However, in both Autroraptor and Buitreraptor the maxillary fenestra is not dorsally displaced, a condition that was considered diagnostic of Unenlagiidae by Novas et al. (2009). In basal birds (e.g. Archaeopteryx, Confusiusornis; Chiappe et al. 1999, Mayr et al. 2007) and in Buitreraptor and Austroraptor 
the maxillary fenestra is very large and round, a plesiomorphic condition widespread among theropods (Hu et al. 2009; ch. H240, state 0).

In consequence, unenlagiids and basal birds lack the dorsally displaced maxillary fenestra diagnostic of Droameosauridae.

20 - Lacrimal "T"-shaped in lateral view (ch. H40). The morphology of the lacrimal is peculiar to dromaeosaurids, in which this bone has a "T"-shaped morphology due to its nearly straight dorsal margin, with well-developed and subequal anterior and posterior processes, and a larger, columnar, and vertically oriented jugal process (Norell and Makovicky 2004). In the remaining theropods, the lacrimal is usually "L"-shaped due to the poor development of its posterior process (Currie 1995). Among Unenlagiidae, the only genus in which the lacrimal is preserved is Austroraptor, which lacks the "T"-shaped condition seen in most dromaeosaurids. On the contrary, it has a short and cranially curved jugal process, a shortened posterior process, and an enlarged anterior process, thus conferring an "L"-shaped lacrimal in side view. In this regard, unenlagiids resemble troodontids and basal birds (e.g., Archaeopteryx, Jeholornis; Zhou and Zhang 2003b, Mayr et al. 2007), in which the lacrimal is "L"-shaped.

21 - Lateral process of the quadrate that touches squamosal and quadratojugal above an enlarged quadrate foramen (ch. H54). The quadrate bone in most dromaeosaurids and Buitreraptor exhibits, in addition to its medial pterygoid process, a well developed lateral bony wing formed by an extension of the anterior margin of the quadrate shaft for contact with the squamosal (Currie 1995, Norell and Makovicky 2004). This morphology, considered to be unique of dromaeosaurids, is also present in Archaeopteryx, as it was first noticed by Walker (1985). In the same way, a lateral process appears to be also present in the basal avialan Confusiusornis (Chiappe et al. 1999), although in this genus it is highly reduced, being represented only by a narrow flange located near the proximal articular head of the bone (Chiappe et al. 1999). The presence of such process in other basal avialans (e.g. Jeholornis, Sapeornis) is difficult to determine due to poor preservation of most of the specimens.

In summary, the presence of a lateral flange in the quadrate of Archaeopteryx suggests that this trait is more widely distributed among paravians than previously thought.

22 - Extension of supratemporal fossa over most of the frontal process of the postorbital. Novas et al. (2009) proposed that this condition may be diagnostic of Dromaeosauridae, including unenlagiids. However, a dorsally excavated frontal process of postorbital is also present in some troodontids (Currie 1985, 1987) and basal birds, including Enantiornithes (Chiappe and Walker 2002), Confusiusornis, and Sapeornis (Chiappe et al. 1999, Chiappe and Walker 2002, Zhou and Zhang 2003b). Regrettably, the dorsal margin of the postorbital is unknown in some basal avialans such as Archaeopteryx, Jeholornis, and Sapeornis. In this way, this condition is here considered as widespread among paravians.

23 - Anterior emargination of supratemporal fossa on frontal sinusoidal (ch. H43). Xu et al. (2000) considered a sinusoidal anterior ridge defining the supratemporal fossae as diagnostic of Dromaeosauridae, a morphology discussed in detail by Xu (2002) and Norell et al. (2006). These authors demonstrated that in most eudromaeosaurids (e.g. Bambiraptor, Saurornitholestes, Deinonychus) and microraptorians (e.g. Sinornithosaurus), with the sole exception of Tsaagan and Dromaeosaurus, the anterior ridge that 
delimitates the supratemporal fossa was sinusoidal (i.e., convex on its lateral side, concave at mid-length, and becoming convex again on its medial side; Xu 2002). In contrast, in the unenlagiids Buitreraptor and Austroraptor, this crest is represented by an anteriorly concave and oblique ridge (Makovicky et al. 2005, Novas et al. 2009; Fig. 5C-D), a condition seen in most theropods, including troodontids and birds.
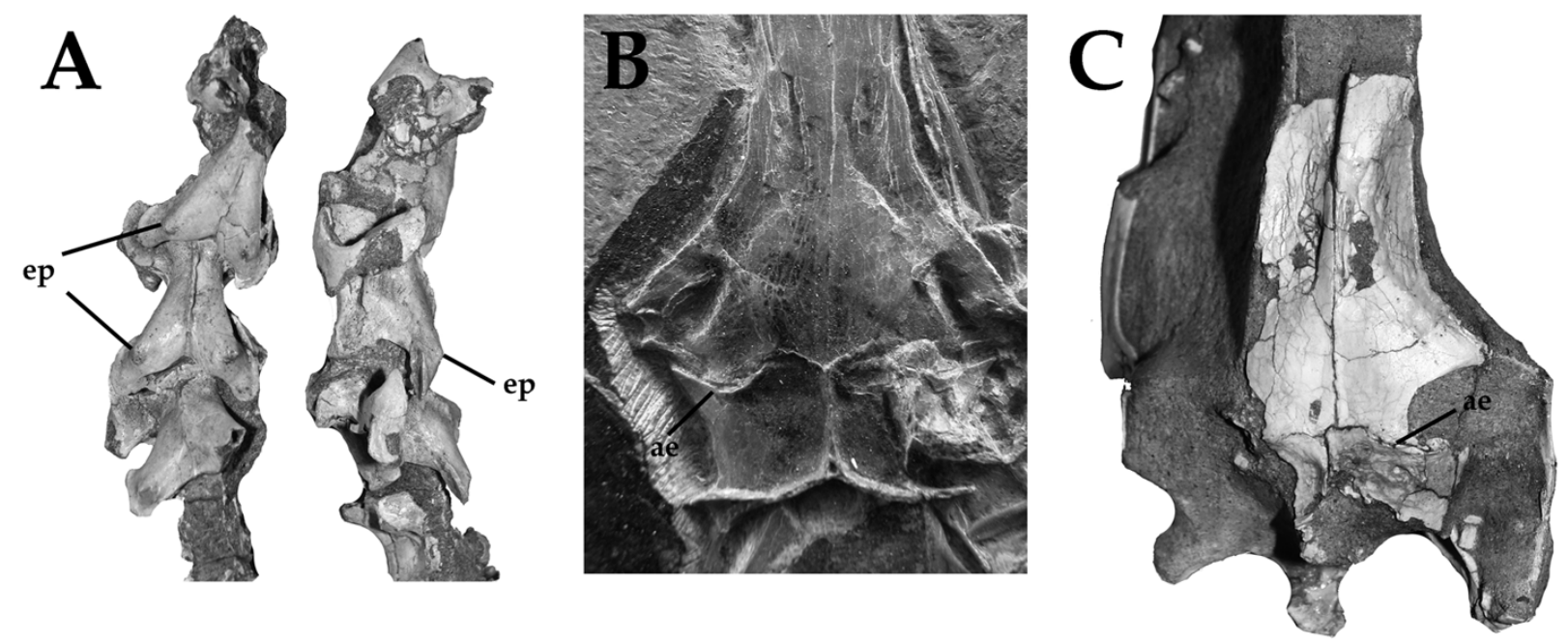

Fig. 5 - A, dorsal and left lateral views of mid-cervical vertebrae of Buitreraptor gonzalezorum (MPCA, 245; holotype); B, dorsal view of skull roof of Sinornithosaurus millenii (IVPP V12811; holotype); C, Dorsal view of skull roof of Buitreraptor gonzalezorum (MPCA, 245; holotype). Scale bar $5 \mathrm{~cm}$. Abbreviations: ae, anterior emargination of supratemporal fossa; ep, epipophyses.

24 - Dentary with subparallel dorsal and ventral edges (ch. H71). This feature was originally noticed by Currie (1995) and later discussed by Xu and $\mathrm{Wu}$ (2001), who affirmed that a parallel-sided dentary is a feature diagnostic of Dromaeosauridae. In fact, along most of its length, the dentary of most dromaeosaurids has subparallel dorsal and ventral margins, usually with the dorsal margin being sligthly concave, and the ventral one convex. On the other hand, in Archaeopteryx the dentary exhibits both dorsal and ventral margins slightly divergent caudally, a condition that may be verified in a variety of other basal avialans, including Jeholornis, Ichthyornis, and Enantiornithes (Zhou and Zhang 2003a, Chiappe and Walker 2002, Clarke 2004). Unfortunately, the dentary in Unenlagiidae is poorly known, being distorted and incompletely preserved in Buitreraptor, and distorted in Austroraptor. However, in both Buitreraptor and Austroraptor, the caudal end of the dentary is clearly deeper than the cranial end, showing a subtriangular contour in lateral view, a condition reminiscent to that of basal birds (Fig. 2A).

25 - Unconstricted teeth (ch. H88). Among derived features interpreted as diagnostic of dromaeosaurids is the lack of constrictions between the crown and the root of the teeth, in contrast with the well-developed constriction present in troodontids and dentate birds (Currie et al. 1990, Martin et al. 1980). However, a detailed analysis of available specimens that were equivocally distributed among dromaeosaurids, suggests that this morphology is not diagnostic of Dromaeosauridae. Although in most dromaeosaurids, including unenlagiids the teeth are unconstricted (Makovicky and Norell 2004, Makovicky et al. 2005, Gianechini et al. 2009), in several dromaeosaurid genera, such as Atrociraptor, Sauror- 
nitholestes, Velociraptor, Sinornithosaurus, and Microraptor, a constriction between the crown and root is present at least in some of their teeth (Currie et al. 1990, Xu et al. 2000, Currie and Varricchio 2004). On the other hand, in Archaeopteryx a constriction between the root and the crown is not always observable, being only seen at the base of some teeth (Elzanowski and Wellnhofer 1996, Martin and Stewart 1999, Martin et al. 1980). In other basal birds, such as Sapeornis and Jeholornis, the teeth appear to lack signs of crown root constriction (Zhou and Zhang 2003a, b). In conclusion, the presence or absence of a basal constriction is a condition difficult to quantify among paravians, and thus is doubtfully diagnostic of any paravian clade.

26 - Epipophyses of cervical vertebrae placed distally on postzygapophyses, above postzygopophyseal facets (ch. H95). Epipophyses of cervical vertebrae in dromaeosaurids are relatively long and slender, and usually surpass the caudal margin of postzygapophyses (Ostrom 1969). On the contrary, available cervicals of Buitreraptor and Austroraptor show that the epipophyses are extremely short and do not reach the caudal end of the postzygapophyses (Makovicky et al. 2005, Novas et al. 2009; Fig. 5AD). Shortened epipophyses are also seen in troodontids such as Troodon and Sinovenator and several avialans, including the enantiornithines Iberomesornis and Gobipteryx, and the basal carinate Ichthyornis (Kurochkin 1996, Sereno 2000, Xu 2002, Clarke 2004, Makovicky and Norell 2004).

In conclusion, the elongate epipophyses present in typical dromaeosaurids (e.g. Ostrom 1969) are absent in unenlagiids.

27 - Anterior cervical centra level with of shorter than posterior extent of neural arch (ch. H96). Although considered by Novas et al. (2009) as diagnostic of Dromaeosauridae, including unenlagiids, the morphology of the posterior margin of the neural arch is variable among paravians. Although in most theropods the neural arch does not approach the posterior level of the vertebral centrum, in dromaeosaurids, the posterior margin of the neural arch approaches the caudal end of the centrum, a condition that may be also seen in several avialans, including Archaeopteryx (HMN 1880), the enantiornithines Iberomesornis and Gobipteryx, the ornithurine Ichthyornis, and some troodontids, such as Troodon and Sinovenator (Kurochkin 1996, Sereno 2000, Xu 2002, Clarke 2004, Makovicky and Norell 2004).

In summary, this trait appears to be more variable and more widespread than previously thought among theropods and may not be considered as diagnostic of Dromaeosauridae.

28 - Parapophyses of posterior dorsal vertebrae distinctly projected on pedicels (ch. H103). Dromaeosaurid dorsal vertebrae are diagnostic in having stalked or pedunculated parapophyses that project laterally far from the centrum, a condition first noticed by Ostrom (1969) and later discussed in detail by Norell and Makovicky (1999). This derived feature, considered to be unique of dromaeosaurids, was reported in unenlagiids (e.g. Unenlagia, Buitreraptor), suggesting that they may belong to this theropod clade (Norell and Makovicky 1999, Makovicky et al. 2005). However, pedunculated parapophyses are probably present in Archaeopteryx (Mayr et al. 2007), but are clearly observed in Confusiusornis (Chiappe et al. 1999), and more derived birds, including Ichthyornis, Baptornis, Patagopteryx and Neornithes (e.g. Anseriformes, Tinamiformes, Galliformes; personal observations) (Martin and Tate 1976, Chiappe 2002, Clarke 2004), as well as alvarezsaurids (Novas 1996). Thus, the presence of stalked or pedunculated parapophyses may be considered as diagnostic of a more inclusive clade (i.e. Maniraptora). 
29 - Middle and posterior dorsal vertebrae pneumatic (ch. H106). This trait was considered by $\mathrm{Hu}$ et al. (2009) as apomorphic of Dromaeosauridae, including unenlagiids. However, the presence of pneumatization on mid and posterior dorsal vertebrae appears to be more widespread than suggested by Hu et al. (2009). In fact, in Archaeopteryx, although dorsal vertebrae are poorly preserved, a real pleurocoel foramen is present behind the diapophyses in the two last dorsal vertebrae (Britt et al. 1998, Elzanowski 2002). A similar pleurocoel is also present in basal birds, such as Jeholornis, Confusiusornis, and Ichthyornis (Chiappe et al. 1999, Zhou and Zhang 2003b, Clarke 2004), suggesting a wide distribution of pneumatic vertebrae among basal birds.

In conclusion, the presence of pneumatic middle and posterior dorsal vertebrae may be considered as diagnostic of Paraves, rather than Dromaeosauridae.

30 - Distal caudal chevrons bifurcate at both ends (ch. H123). Although Makovicky et al. (2005) proposed that this feature united Unenlagiidae with the remaining dromaeosaurids, this condition is also present in basal avialans and troodontids. In fact, cranially and caudally forked chevrons are seen among avialans in Jeholornis and Archaeopteryx (Wellnhofer 1992, Forster et al. 1998, Zhou and Zhang 2003a), and in troodontids they are present in the basal forms Anchiornis and $\mathrm{Mei}$ (Xu et al. 2008, Xu and Norell 2004). In summary, we consider this feature as diagnostic of the node Paraves.

\section{1 - Manual unguals with dorsal arch higher than level of dorsal extremity of proximal articular} surface (ch. H296). First considered as diagnostic of Dromaeosauridae by Zheng et al. (2009), this condition is widespread among birds with the exclusion of Wellnhoferia and Archeopteryx (Hu et al. 2009). Moreover, the same morphology is seen in the basalmost troodontid Anchiornis (Hu et al. 2009). This may suggest a wider distribution of this trait than previously thought.

32 - Metatarsal II distally ginglymoid (ch. H198). The distal end of metatarsal II has a deep and well-excavated distal trochlea forming a ginglymous articular surface, which was considered as diagnostic of Deinonychosauria by Gauthier (1986). More recently, this condition was suggested as apomorphic of Dromaeosauridae, including Unenlagiidae (Novas and Pol 2005, Makovicky et al. 2005). Curiously, in the basal dromaeosaurids Sinornithosaurus and Microraptor the distal end of metatarsal II lacks a deep excavation on its cranial surface (Xu 2002, Hwang et al. 2002). The same is also true for Unenlagia, Rahonavis, and Buitreraptor, in which the distal end of metatarsal II is poorly excavated in anterior view (Forster et al. 1998, Novas and Pol 2005, Makovicky et al. 2005; Fig. 4). Although a distal ginglymoid is clearly absent in several basal avialans, including Archaeopteryx, Jeholornis and Zhongornis (Mayr et al. 2007, Zhou and Zhang 2003a, Gao et al. 2008), in other early birds, such as Enantiornithes, Ichthyornis, Apsaravis, and Sapeornis a distal ginglymoid is present and well developed, conforming a deep distal trochlea on metatarsal II (Chiappe and Walker 2002, Clarke and Norell 2002, Zhou and Zhang 2003b, Clarke 2004, Xu et al. 2008). Thus, the equivocal distribution of this condition, suggests that the excavated metatarsal II trochlea may not be informative to diagnose Dromaeosauridae.

33 - Pedal phalanx II-2 strongly constricted dorsoventrally at mid-shaft. This condition, first noticed as diagnostic of Dromaeosauridae by Rauhut and Werner (1995) was considered as present in Unenlagia (= Neuquenraptor) by Novas and Pol (2005). This morphology is probably correlated with the special- 
ized articulation for the enlarged and trenchant ungual II-3, as early noted by Ostrom (1969). Although this character is clearly present in Dromaeosauridae and unenlagiids, more recent findings indicate that similar phalangeal morphology is present in basal avialans, such as Jeholornis and Archaeopteryx (Paul 2002, Zhou and Zhang 2003a), as well as troodontids (Norell and Makovicky 2004), suggesting that this trait may be diagnostic of paravians rather than of Dromaeosauridae.

34 - Pedal phalanx II-1 shorter than pedal phalanx IV-1 (ch. H342). Hu et al. (2009) suggested that this condition may be considered as an apomorphy shared by all dromaeosaurids. In troodontids, as well as in basal birds (e.g., Archaeopteryx, Jeholornis, Confusiusornis; Chiappe et al. 1999, Paul 2002, Zhou and Zhang 2003b), the pedal phalanx II-1 is much longer than phalanx IV-1, a morphology that is clearly different from the abbreviated condition of phalanx II-1 seen in dromaeosaurids, including Rahonavis (Forster et al. 1998). In the unenlagiids Buitreraptor, Unenlagia, and Austroraptor the phalanx IV-1 remains unknown, and thus the present character cannot be evaluated properly.

35 - Ungual of pedal digit II strongly compressed laterally and with collateral grooves asymmetrically arranged. This condition, previously proposed as diagnostic of dromaeosaurids (Rauhut and Werner 1995), is also seen in Rahonavis, Buitreraptor, and Unenlagia (Forster et al. 1998, Calvo et al. 2004, Makovicky et al. 2005). However, the distribution of this trait is ambiguous among basal birds (e.g. Archaeopteryx, Jeholornis, Zhongornis, Sapeornis, Protopteryx) because their respective ungual phalanges are preserved in two dimensions.

36 - Hallucal ungual strongly curved (ch. H319). Although a strongly curved hallucal ungual was considered as diagnostic of Dromaeosauridae by $\mathrm{Hu}$ et al. (2009), this condition is widespread among basal birds, including Archaeopteryx, Wellnhoferia, Sapeornis, Jeholornis and Enantiornithes, among others (Elzanowski 2002, Zhou and Zhang 2003a, Martin 1995). In these birds the presence of a large and curved hallucal ungual, in association with a reversed hallux, was considered as indicative of arboreal capabilities (Zhou and Zhang 2003b). This indicates that the curvature of pedal ungual of digit I is more widely distributed among paravians than suggested by Hu et al. (2009).

As is the case of Deinonychosauria, several traits considered as diagnostic of Dromaeosauridae by previous authors are not preserved in any unenlagiid specimen. Among them are: posterior process of premaxilla excluding the maxilla from naris, caudal margin of nares farther rostral than the rostral border of the antorbital fossa, large spike on the medial inflected process of the articular, absence of an accesory tympanic recess to the crista interfenestralis, and elongate paroccipital process with parallel dorsal and ventral edges that twist rostrolaterally distally (Norell et al. 2006, Turner et al. 2007b, Hu et al. 2009).

\section{CONCLUSIONS}

After recoding several traits in the data matrix of the most integrative and recent analysis of coelurosaurian phylogeny (Hu et al. 2009), several changes in the tree topology are observed.

Our phylogeny resembles that of Hu et al. (2009) in depicting a resolved Paraves, which is diagnosed by an extensive list of features, including acromial margin of the scapula with anterior edge laterally everted, proximal end of ulna divided into two fossae, large and trenchant pedal ungual claw on 
digit II, among other outstanding characters (see Appendix III). Our results also indicate that Dromaeosauridae and Deinonychosauria are both probably monophyletic (see Appendix III for a complete list of synapomorphies).

However, our phylogeny clearly departs from previous analyses (Norell et al. 2001, Xu et al. 2002, 2008, Xu and Norell 2004, Novas and Pol 2005, Novas et al. 2009, Hu et al. 2009) in the exclusion of Unenlagiidae from both Dromaeosauridae and Deinonychosauria. In fact, unenlagiids appear to be more nearly related to Aves than to other theropods. Both unenlagiids and birds share, among other character-states, dentaries with well-defined interdental plates, preacetabular part of ilium markedly longer than postacetabular portion, widely separated distal ends of ischia, and coracoid with acrocoracoid process (see Appendix III). In the same way, some authors noted additional similarities between unenlagiids and birds, as for example elongate forelimbs, vertically oriented pubes, and numerous details of scapular anatomy (Paul 2002, Senter 2007).

Unenlagiidae is here considered monophyletic and includes the genera Rahonavis, Buitreraptor, Unenlagia, and Austroraptor, which are diagnosed by pedal phalanx II-2 with transversely narrow posteroventral keel, dorsal margin of postacetabular blade of ilium concave, and ischium with posterior end deeply concave (see Appendix III). Within Unenlagiidae, Unenlagia and Buitreraptor + Austroraptor share, with the exclusion of Rahonavis, the presence of a tuber along the dorsal edge of ilium and obturator process of ischium forming an acute angle in lateral view. Moreover, Buitreraptor and Austroraptor share non-pneumatic middle and posterior dorsal vertebral centra.

Rahonavis was included within Unenlagiidae in the present analysis, a result that is in agreement with the proposal of Makovicky et al. (2005) and in contrast with some phylogenies that posit Rahonavis well internested among Aves (Zhou and Zhang 2003a, Hwang et al. 2002, Turner et al. 2007b, Xu et al. 2008). However, the incomplete nature of the known specimens, together with several similarities shared between Rahonavis and birds noted by previous authors (Forster et al. 1998, Novas 2004, Xu et al. 2008), indicate that more detailed studies may relocate Rahonavis within Aves.

In conclusion, the phylogenetic position of Unenlagia and its kin, as sister group of Aves, allows us to further investigate in detail the peculiar anatomy of this theropod group, which will raise questions about phylogenetic and functional significances, leading us to consider with better information poorly known aspects of the early evolution of avian flight (e.g., postural activities, flapping abilities).

\section{ACKNOWLEDGMENTS}

We thank D. Pol for the photographs of Microraptor and Jeholornis. We thank G. Mayr for sharing with us information about the $10^{\text {th }}$ Archaeopteryx skeleton. We acknowledge F. Gianechini, and M. Ezcurra for the photographs of Buitreraptor and Austroraptor, as well as, fruitful discussions about theropod phylogeny. Two annonymous reviewers offered valuable observations that improved the quality of this paper.

\section{RESUMO}

No presente trabalho analisou-se a posição filogenética do clado derivado de terópodas gondwânicos Unenlagiidae. Embora este grupo tenha sido frequentemente considerado como profundamente enraizado entre Deinonychosauria e 
Dromaeosauridae, grande parte das características que sustentam esta interpretação é no mínimo conflitiva. A modificação de bancos de dados integrativos, tal como a recentemente publicada por Hu et al. (2009), produz mudanças significativas na distribuição topológica dos táxons dentro de Deinonychosauria, representando unenlagiids fora deste clado. Nossa análise recupera, em contrapartida, um Avialae monofilético formado por Unenlagiidae e Aves.

Palavras-chave: Gondwana, Deinonychosauria, Dromaeosauridae, Unenlagiidae, Avialae.

\section{REFERENCES}

BARSBOLD R. 1974. Saurornithoididae, a new family of small theropod dinosaurs from central Asia and North America. Palaeont Pol 27: 5-13.

BONAPARTE JF. 1999. Tetrapod faunas from South America and India: a palaeobiogeographic interpretation. Proc India Acad Sci 65: 427-437.

Britt BB, Makovicky PJ, Gauthier J And Bonde N. 1998. Postcranial pneumatization in Archaeopteryx. Nature 395: 374-376.

Calvo JO, Porfiri JD And Kellner AWA. 2004. On a new maniraptoran dinosaur (Theropoda) from the Upper Cretaceous of Neuquén, Patagonia, Argentina. Arquiv Mus Nac 62: 549-566.

ChIAPPE LM. 1993. Enantiornithean (Aves) tarsometatarsi from the Cretaceous Lecho Formation of Northwestern Argentina. Am Mus Novit 3083: 1-27.

Chiappe LM. 2001. Phylogenetic relationships among baal birds. In: Gauthier J And Gall LF (Eds), New perspectives on the origin and evolution of birds. Special Publications of the Peabody Museum of Natural History, Yale University, New Haven, Connecticut, USA, p. 125-139.

Chiappe LM. 2002. Osteology of the flightless Patagopteryx deferrariisi from the Late Cretaceous of Patagonia (Argentina). In: Chiappe LM AND WitMer LM (Eds), Mesozoic birds: above the heads of dinosaurs. Berkeley University Press, p. 281-316.

Chiappe LM, Ji S, Ji Q And Norell MA. 1999. Anatomy and systematics of Confusiusornithidae from the late Mesozoic of northeastern China. Bull Amer Mus Nat Hist 242: 1-89.

ChiAPPe LM AND WALKer CA. 2002. Skeletal morphology and systematics of Cretaceous Euenantiornithes (Ornithothoraces: Enantiornithes). In: ChiApPE LM AND Witmer LM (Eds), Mesozoic birds: above the heads of dinosaurs. Berkeley: Berkeley University Press, USA, p. 168-218.

ClARKE JA. 2004. Morphology, phylogenetic taxonomy, and systematics of Ichthyornis and Apatornis (Avialae: Ornithurae). Bull Amer Mus Nat Hist 242: 1-179.

Clarke JA AND Norell MA. 2002. The morphology and phylogenetic position of Apsaravis ukhaana from the Late Cretaceous of Mongolia. Amer Mus Novit 3387: 1-46.

CURRIE PJ. 1985. Cranial anatomy of Stenonychosaurus inequalis (Saurischia, Theropoda) and its bearing on the origin of birds. Canadian Jour Earth Sci 22: 1643-1658.

CURRIE PJ. 1987. Bird-like characteristics of the jaws and teeth of troodontid theropod (Dinosauria, Saurischia). J Vert Paleont 7: 72-81. 
CURRIE PJ. 1995. New information of the anatomy and relationships of Dromaeosaurus albertensis (Dinosauria: Theropoda). J Vert Paleont 15: 576-591.

CuRrie PJ, Rigby JK and SloAn RE. 1990. Theropod teeth from the Judith River Formation of southern Alberta, Canada. In: CARPENTER K ET AL. (Eds), Dinosaur Systematics: Perspectives and Approaches, p. 107-125.

CURrie PJ And VARricchio DJ. 2004. A new dromaeosaurid from the Horseshoe Canyon Formation (Upper Cretaceous) of Alberta, Canada. In: CURRIE PJ ET AL. (Eds), Feathered Dragons: Studies from the transition from dinosaurs to birds. Indiana University Press, p. 113-132.

Elzanowski A. 2002. Archaeopterygidae (Upper Jurassic of Germany). In: Chiappe LM And Witmer LM (Eds), Mesozoic birds: above the heads of dinosaurs. Berkeley: Berkeley University Press, USA, p. 129-159.

Elzanowski A AND Wellnhofer P. 1996. Cranial morphology of Archaeopteryx: evidence from the seventh skeleton. J Vert Paleont 16: 81-94.

Forster C, Sampson S, Chiappe LM and Krause D. 1998. The theropod ancestry of birds: new evidence from the Late Cretaceous of Madagascar. Science 279: 1915-1919.

Gao C, Chiappe Lm, Meng Q, O’Connor JK, Wang X, Cheng X and Liu J. 2008. A new basal lineage of Early Cretaceous birds from China and its implications on the evolution of the avian tail. Palaeontology 51: 775-791.

GaUthier JA. 1986. Saurischian monophyly and the origin of birds. Mem Calif Acad Sci 8: 1-46.

Gianechini FA, Apesteguía S And Makovicky PJ. 2009. The unusual dentiton of Buitreraptor gonzalezorum (Theropoda, Dromaeosauridae), from Patagonia, Argentina: new insights on the unenlagine teeth. XXIV Jornadas Argentinas de Paleontología de Vertebrados, San Rafael, Mendoza, Abstract Book 36.

Goloboff PA, FARris FA AND NixOn C. 2003. NONA. Program and documentation. Published by the authors.

Hu D, Hou L, Zhang L AND Xu X. 2009. A pre-Archaeopteryx troodontid theropod from China with long feathers on the metatarsus. Nature 461: 640-643.

Hwang SH, Norell MA, Qiang J And Keqin G. 2002. New specimens of Microraptor zhaoianus (Theropoda: Dromaeosauridae) from Northeastern China. Amer Mus Novit 3381: 44.

KUROChKIN EN. 1996. A new enantiornithid of the Mongolian Late Cretaceous, and a general apparaisal of the infraclass Enantiornithes (Aves). Russian Acad Sci, Paleont Special Issue 8: 1-50.

LONGRICH NR AND CURRIE PJ. 2008. A microraptorine (Dinosauria-Dromaeosauridae) from the Late Cretaceous of North America. PNAS 106: 5002-5007.

Makovicky PJ, Apesteguía S And Agnolín FL. 2005. The earliest dromaeosaurid theropod from South America. Nature 437: 1007-1011.

Makovicky PJ And Norell MA. 2004. Troodontidae. In: Weishampel DB, Dodson P and Osmólska H (Eds), The Dinosauria. University of California Press, p. 184-195.

Makovicky PJ, Norell MA, Clark JM And Rowe T. 2003. Osteology and relationships of Byronosaurus jaffei (Theropoda: Troodontidae). Amer Mus Novit 3402: 1-32.

MARTIN LD. 1995. The Enantiornithes: terrestrial birds of the Cretaceous. Courier Forschungsinstitut Senckenberg 181: $23-36$. 
MARTIN LD AND STEWART JD. 1999. Implantation and replacement of bird teeth. Smith Contrib Paleobiol 89: $295-300$.

Martin LD, Stewart JD And Whetstone KN. 1980. The origin of birds: the structure of tarsus and teeth. The Auk 97: 86-93.

MARTIN LD And TATE J. 1976. The skeleton of Baptornis advenus (Aves: Hesperornithiformes). Smith Contrib Paleobiol 27: 35-66.

Mayr G, Pohl B, Hartman S and Peters DS. 2007. The tenth skeletan specimen of Archaeopteryx. Zool Jour Lin Soc 149: 97-116.

Mayr G, Pohl B And Peters DS. 2005. A well preserved Archaeopteryx specimen with theropod features. Science 310: 1483-1486.

Norell MA, Clark JM And Makovicky PJ. 2001. Phylogenetic relationships among coelurosaurian theropods. In: GaUthiER J AND GALl LF (Eds), New perspectives on the origin and early evolution of birds. New Haven: Peabody Museum of Natural History, Yale University, p. 49-68.

Norell Ma, Clark JM, Turner AH, Makovicky PJ, Barsbold R and Rowe T. 2006. A new dromaeosaurid theropod from Ukhaa Tolgod (Ömnögov, Mongolia). Amer Mus Novit 3545: 1-51.

NORELl MA AND MAKOVICKY PJ. 1999. Important features of the dromaeosaur skeleton II: information from newly collected specimens of Velociraptor mongoliensis. Amer Mus Novit 3282: 1-45.

Norell MA and Makovicky PJ. 2004. Dromaeosauridae. In: Weishampel DB, Dodson P and OsmólSKA H (Eds), The Dinosauria, p. 196-209.

Novas FE. 1996. Alvarezsauridae, Cretaceous maniraptorans from Patagonia and Mongolia. Mem Queens Mus 39: $675-702$.

Novas FE. 2004. Avian traits in the ilium of Unenlagia comahuensis (Maniraptora, Avialae). In: CURRIE PJ ET AL. (Eds), Feathered Dragons: Studies on the Transition from Dinosaurs to Birds. Bloomington, Indiana University Press, p. 150-166.

Novas FE AND POL D. 2005. New evidence on deinonychosaurian dinosaurs from the Late Cretaceous of Patagonia. Nature 433: 858-861.

Novas Fe, Pol D, Canale Ji, Porfiri JD and Calvo JO. 2009. A bizarre Cretaceous theropod dinosaur from Patagonia and the evolution of Gondwanan dromaeosaurids. Proc Royal Soc London B 126: 1101-1107.

Novas F AND PUERTA P. 1997. New evidence concerning avian origins from the Late Cretaceous of NW Patagonia. Nature 387: 390-392.

Ostrom JH. 1969. Osteology of Deinonychus antirrhopus, an unusual theropod from the Lower Cretaceous of Montana. Bull Peabody Mus Nat Hist 30: 1-165.

PAUL GS. 2002. Dinosaurs of the Air. The John Hopkins University Press, p. 1-460.

Rauhut OWM. 2003. The interrelationships and evolution of basal theropod dinosaurs. Special Papers Palaeont 69: $1-213$.

RAUHUt OWM AND WeRnER C. 1995. First record of the family Dromaeosauridae (Dinosauria: Theropoda) in the Cretaceous of Gondwana (Wadi Milk Formation, Northern Sudan). Paläont Zeitsch 69: 475-489. 
RICH TH AND VICKERS-RICH P. 1993. Neoceratopsians and ornithomimosaurs: Dinosaurs of Gondwana origin? Natl Geogr Res Expl 10: 129-131.

Senter P. 2007. A new look at the phylogeny of Coelurosauria (Dinosauria: Theropoda). J Syst Palaeont 5: 429-463.

SERENO P. 2000. Iberomesornis romerali (Aves, Ornithothoraces) reevaluated as an Early Cretaceous enantiornithine. Neues Jahr Geol Paleont 215: 365-395.

SuEs H-D. 1977. Dentaries of small theropods from the Judith River Formation of Alberta, Canada. Can J Earth Sci 14: $587-592$.

Turner AH, Hwang SH and Norell MA. 2007a. A small derived theropod from Oösh, Early Cretaceous, Baykhangor Mongolia. Amer Mus Novit 3557: 1-27.

Turner AH, Pol D, Clarke JA, Erickson GM and Norell MA. 2007b. A basal dromaeosaurid and size evolution preceding avian flight. Science 317: 1378-1381.

WALKer AD. 1985. The braincase of Archaeopteryx. In: Hecht MK, Ostrom JH, Viohl G AND WellNHOFER P (Eds), The beginnings of birds: Proceedings of the International Archaeopteryx Conference, Eichstätt, 1985. Freunde des Jura-Museum Eichstätt, Eichstätt, p. 123-134.

Wellnhofer P. 1992. A new specimen of Archaeopteryx from the Solnhofen limestone. Nat Hist Mus Los Angeles County, Sci Ser 36: 3-24.

XU X. 2002. Deinonychosaurian fossils from the Jehol Group of western Liaoning and the coelurosaurian evolution. Dissertation for the Doctoral Degree. Beijing: Chinese Academy of Sciences, $322 \mathrm{p}$.

XU X AND Norell MA. 2004. A new troodontid dinosaur from China with avianlike sleeping posture. Nature 431: 838-841.

Xu X, Norell MA, Wang X, Makovicky P And WU X. 2002. A basal troodontid from the Early Cretaceous of China. Nature 415: 780-784.

XU X, WANG X-L AND WU X-C. 1999. A dromaeosaurid dinosaur with a filamentous integument from the Yixian Formation of China. Nature 401: 262-266.

XU X AND WU X-C. 2001. Craneal morphology of Sinornithosaurus millenii Xu et al. 1999 (Dinosauria: Theropoda: Dromaeosauridae) from the Yixian Formation of Liaoning, China. Canadian J Earth Sci 38: $1739-1752$.

Xu X And Zhang F. 2005. A new maniraptoran dinosaur from China with long feathers on the metatarsus. Naturwissenchaften 92: 173-177.

Xu X, Zhao Q, norell Ma, Sullivan C, Hone D, Erickson PG, Wang X, Han F and Guo Y. 2008. A new feathered dinosaur fossil that fills a morphological gap in avian origin. Chinese Sci Bull 54: 430-435.

Xu X, Zhou Z And WAng X. 2000. The smallest known non-avian theropod dinosaur. Nature 408: 705-708.

Xu X, Zhou Z, Wang X, Huang X, Zhang F and Du X. 2003. Four winged dinosaurs from China. Nature 421: $335-340$.

Zheng X, Xu X, You H, Zhao Q and Dong Z. 2009. A short-armed dromaeosaurid from the Jehol Group of China with implications for early dromaeosaurid evolution. Proc Royal Soc London B 277: 211-217. 
ZHOU ZH AND ZHANG FC. 2003a. Anatomy and systematics of the primitive bird Sapeornis chaoyangensis from the Early Cretaceous of Liaoning, China. Can J Earth Sci 40: 731-747.

Zhou ZH AND Zhang FC. 2003b. Jeholornis compared to Archaeopteryx, with a new understanding of the earliest avian evolution. Naturwissenchaften 90: 220-225.

Zhou ZH and Zhang Zhineng Li F. 2009. A new Lower Cretaceous bird from China and tooth reduction in early avian evolution. Proc Royal Soc London B 277: 219-227.

\section{APPENDIX I - Character list}

1. Vaned feathers on forelimb symmetric (0) or asymmetric (1).

2. Orbit round in lateral or dorsolateral view (0) or dorsoventrally elongate (1).

3. Anterior process of postorbital projects into orbit (0) or does not project into orbit (1).

4. Postorbital in lateral view with subhorizontal anterior (frontal) process (0) or frontal process diagonal (anterior tip of process higher than base of process) (1).

5. Postorbital bar parallels quadrate, lower temporal fenestra rectangular in shape ( 0 ) or jugal and postorbital approach or contact quadratojugal to constrict lower temporal fenestra (1).

6. Otosphenoidal crest vertical on basisphenoid and prootic, and does not border an enlarged pneumatic recess (0) or welldeveloped, crescent shaped, thin crest forms anterior edge of enlarged pneumatic recess (1).

7. Crista interfenestralis confluent with lateral surface of prootic and opisthotic (0) or distinctly depressed within middle ear opening (1). 8. Subotic recess (pneumatic fossa ventral to fenestra ovalis) absent (0) or present (1).

9. Basisphenoid recess present between basisphenoid and basioccipital (0) or entirely within basisphenoid (1) or absent (2).

10. Posterior opening of basisphenoid recess single (0) or divided into two small, circular foramina by a thin bar of bone (1).

11. Base of cultriform process not highly pneumatized (0) or base of cultriform process (parasphenoid rostrum) expanded and pneumatic (parasphenoid bulla) (1).

12. Basipterygoid processes ventral or anteroventrally projecting (0) or lateroventrally projecting (1).

13. Basipterygoid processes well developed, extending as a distinct process from the base of the basisphenoid (0) or processes abbreviated or absent (1).

14. Basipterygoid processes solid (0) or processes hollow (1).

15. Basipterygoid recesses on dorsolateral surfaces of basipterygoid processes absent (0) or present (1).

16. Depression for pneumatic recess on prootic absent (0) or present as dorsally open fossa on prootic/opisthotic (1) or present as deep, posterolaterally directed concavity (2).

17. Accessory tympanic recess dorsal to crista interfenestralis absent (0) small pocket present (1) or extensive with indirect pneumatization (2).

18. Caudal (posterior) tympanic recess absent ( 0 ) present as opening on anterior surface of paroccipital process (1) or extends into opisthotic posterodorsal to fenestra ovalis, confluent with this fenestra (2).

19. Exits of C.N. X-XII flush with surface of exoccipital (0) or cranial nerve exits located together in a bowl-like basisphenoid depression (1).

20. Maxillary process of premaxilla contacts nasal to form posterior border of nares (0) or maxillary process reduced so that maxilla participates broadly in external naris (1) or maxillary process of premaxilla extends posteriorly to separate maxilla from nasal posterior to nares (2). 
21. Internarial bar rounded (0) or flat (1).

22. Crenulate margin on buccal edge of premaxilla absent (0) or present (1).

23. Caudal margin of naris farther rostral than (0), or nearly reaching or overlapping (1), the rostral border of the antorbital fossa.

24. Premaxillary symphysis acute, V-shaped (0) or rounded, U-shaped (1).

25. Secondary palate short (0) or long, with extensive palatal shelves on maxilla (1).

26. Palatal shelf of maxilla flat $(0)$ or with midline ventral "tooth-like" projection (1).

27. Pronounced, round accessory antorbital fenestra absent (0) or present (1).

28. Accessory antorbital fossa situated at rostral border of antorbital fossa (0) or situated posterior to rostral border of fossa (1).

29. Tertiary antorbital fenestra (fenestra promaxillaris) absent (0) or present (1).

30. Antorbital fossa without distinct rim ventrally and anteriorly (0) or with distinct rim composed of a thin wall of bone (1).

31. Narial region apneumatic or poorly pneumatized (0) or with extensive pneumatic fossae, especially along posterodorsal rim of fossa (1).

32. Jugal and postorbital contribute equally to postorbital bar ( 0 ) or ascending process of jugal reduced and descending process of postorbital ventrally elongate (1).

33. Jugal quadratojugal process tall beneath lower temporal fenestra, twice or more as tall dorsoventrally as it is wide transversely

(0) or rod-like (1) or concealed by quadratojugal (2).

34. Jugal pneumatic recess in posteroventral corner of antorbital fossa present (0) or absent (1).

35. Medial jugal foramen present on medial surface ventral to postorbital bar (0) or absent (1).

36. Quadratojugal without horizontal process posterior to ascending process (reversed "L" shape) (0) or with process (i.e., inverted "T" or "Y" shape) (1).

37. Jugal and quadratojugal separate (0) or quadratojugal and jugal fused and not distinguishable from one another (1).

38. Supraorbital crests on lacrimal in adult individuals absent (0) or dorsal crest above orbit (1) or lateral expansion anterior and dorsal to orbit (2).

39. Enlarged foramen or foramina opening laterally at the angle of the lacrimal, absent (0) or present (1).

40. Lacrimal posterodorsal process absent (inverted "L" shaped) (0) or lacrimal " $T$ " shaped in lateral view (1) or anterodorsal process much longer than posterior process (2) or posterodorsal process subvertical (3).

41. Prefrontal large, dorsal exposure similar to that of lacrimal (0) or greatly reduced in exposure (1) or without exposure (2).

42. Frontals narrow anteriorly as a wedge between nasals ( 0$)$ or end abruptly anteriorly, suture with nasal transversely orientated (1) or suture with nasals "W"-shaped (2).

43. Anterior emargination of supratemporal fossa on frontal straight or slightly curved ( 0 ) or strongly sinusoidal and reaching onto postorbital process (1).

44. Frontal postorbital process (dorsal view): smooth transition from orbital margin (0) or sharply demarcated from orbital margin (1).

45. Frontal edge smooth in region of lacrimal suture (0) or edge notched (1).

46. Dorsal surface of parietals flat, lateral ridge borders supratemporal fenestra (0) or parietals dorsally convex with very low sagittal crest along midline (1) or dorsally convex with well developed sagittal crest (2).

47. Parietals separate (0) or fused (1).

48. Descending process of squamosal parallels quadrate shaft (0) or nearly perpendicular to quadrate shaft (1).

49. Descending process of squamosal contacts quadratojugal (0) or does not contact quadratojugal (1). 
50. Posterolateral shelf on squamosal overhanging quadrate head absent (0) or present (1).

51. Dorsal process of quadrate single headed (0) or with two distinct heads, a lateral one contacting the squamosal and a medial head contacting the braincase (1).

52. Quadrate vertical (0) or strongly inclined anteroventrally so that distal end lies far forward of proximal end (1).

53. Quadrate solid (0) or hollow, with depression on posterior surface (1).

54. Lateral border of quadrate shaft straight (0) or with lateral tab that touches squamosal and quadratojugal above an enlarged quadrate foramen (1).

55. Foramen magnum subcircular, slightly wider than tall (0) or oval, taller than wide (1).

56. Occipital condyle without constricted neck (0) or subspherical with constricted neck (1).

57. Paroccipital process elongate and slender, with dorsal and ventral edges nearly parallel (0) or process short, deep with convex distal end (1).

58. Paroccipital process straight, projects laterally or posterolaterally (0) or distal end curves ventrally, pendant (1).

59. Paroccipital process with straight dorsal edge (0) or with dorsal edge twisted rostrolaterally at distal end (1).

60. Ectopterygoid with constricted opening into fossa (0) or with open ventral fossa in the main body of the element (1).

61. Dorsal recess on ectopterygoid absent (0) or present (1).

62. Flange of pterygoid well developed (0) or reduced in size or absent (1).

63. Palatine and ectopterygoid separated by pterygoid (0) or contact (1).

64. Palatine tetraradiate, with jugal process (0) or palatine triradiate, jugal process absent (1).

65. Suborbital fenestra similar in length to orbit (0) or about half or less than half orbital length (1) or absent (2).

66. Symphyseal region of dentary broad and straight, paralleling lateral margin (0) or medially recurved slightly (1) or strongly recurved medially (2).

67. Dentary symphyseal region in line with main part of buccal edge (0) or abruptly downturned at rostral end (1) or dentary ramus gradually, weakly downturned through its length (2).

68. Mandible without coronoid prominence (0) or with coronoid prominence (1).

69. Posterior end of dentary without posterodorsal process dorsal to mandibular fenestra ( 0 ) or with dorsal process above anterior end of mandibular fenestra (1) or with elongate, strongly arched dorsal process extending over most of fenestra (2).

70. Labial face of dentary flat (0) or with lateral ridge and inset tooth row (1).

71. Dentary subtriangular in lateral view (0) or with subparallel dorsal and ventral edges (1).

72. Nutrient foramina on external surface of dentary superficial (0) or lie within deep groove (1).

73. External mandibular fenestra oval (0) or subdivided by a spinous rostral process of the surangular (1).

74. Internal mandibular fenestra small and slit-like (0) or large and rounded (1).

75. Foramen in lateral surface of surangular rostral to mandibular articulation, absent (0) or present (1).

76. Splenial not widely exposed on lateral surface of mandible $(0)$ or exposed as a broad triangle between dentary and angular on lateral surface of mandible (1).

77. Coronoid ossification large (0) or only a thin splint (1) or absent (2).

78. Articular without elongate, slender medial, posteromedial, or mediodorsal process from retroarticular process $(0)$ or with process (1).

79. Retroarticular process short, stout (0) or elongate and slender (1).

80. Mandibular articulation surface as long as distal end of quadrate (0) or twice or more as long as quadrate surface, allowing anteroposterior movement of mandible (1). 
81. Premaxilla toothed (0) or edentulous (1).

82. Second premaxillary tooth approximately equivalent in size to other premaxillary teeth $(0)$ or second tooth markedly larger than third and fourth premaxillary teeth (1) or first premaxillary tooth huge, other premaxillary teeth tiny (2) or first premaxillary tooth larger than the others but all premaxillary teeth tiny (3).

83. Maxilla toothed (0) or edentulous (1).

84. Maxillary and dentary teeth serrated (0) or some without serrations anteriorly (except at base in S. mongoliensis) (1) or all without serrations (2).

85. Dentary and maxillary teeth large, less than 25 in dentary (0) or large number of small teeth (25 or more in dentary) (1) or small number of dentary teeth (_11) (2) or dentary without teeth (3).

86. Serration denticles large (0) or small (1).

87. Serrations simple, denticles convex (0) or distal and often mesial edges of teeth with large, hooked denticles that point toward the tip of the crown (1).

88. Teeth constricted between root and crown (0) or root and crown confluent (1).

89. Dentary teeth evenly spaced (0) or anterior dentary teeth smaller, more numerous, and more closely appressed than those in middle of tooth row (1).

90. Dentaries lack distinct interdental plates (0) or with interdental plates medially between teeth (1).

91. In cross section, premaxillary tooth crowns sub-oval to sub-circular (0) or asymmetrical (D-shaped in cross section) with flat lingual surface (1) or first premaxillary tooth with flat lingual surface, other premaxillary teeth without flat lingual surfaces (2).

92. Number of cervical vertebrae: $10(0)$ or 12 or more (1).

93. Axial epipophyses absent or poorly developed, not extending past posterior rim of postzygopophyses (0) or large and posteriorly directed, extend beyond postzygapophyses (1).

94. Axial neural spine flared transversely (0) or compressed mediolaterally (1).

95. Epipophyses of cervical vertebrae placed distally on postzygapophyses, above postzygopophyseal facets (0) or placed proximally, proximal to postzygapophyseal facets (1).

96. Anterior cervical centra level with or shorter than posterior extent of neural arch (0).

or centra extending beyond posterior limit of neural arch (1).

97. Carotid process on posterior cervical vertebrae absent (0) or present (1).

98. Anterior cervical centra subcircular or square in anterior view (0) or distinctly wider than high, kidney shaped (1).

99. Cervical neural spines anteroposteriorly long and dorsoventrally tall (0) or anteroposteriorly short, dorsoventrally low and centred on neural arch, giving arch an "X" shape in dorsal view (1) or anteroposteriorly short and dorsoventrally tall (2) or anteroposteriorly long and dorsoventrally short (3).

100. Cervical centra with one pair of pneumatic openings (0) or with two pairs of pneumatic openings (1).

101. Cervical and anterior trunk vertebrae amphiplatyan (0) or opisthocoelous (1).

102. Anterior trunk vertebrae without prominent hypapophyses (0) or with large hypapophyses (1).

103. Parapophyses of posterior trunk vertebrae flush with neural arch (0) or distinctly projected on pedicels (1).

104. Hyposphene-hypantrum articulations in trunk vertebrae absent (0) or present (1).

105. Zygapophyses of trunk vertebrae abutting one another above neural canal, opposite hyposphenes meet to form lamina ( 0 ), or zygapohyses placed lateral to neural canal and separated by groove for interspinuous ligaments, hyposphens separated (1).

106. Middle and posterior dorsal vertebrae not pneumatic (0) or pneumatic (1). 
107. Transverse processes of anterior dorsal vertebrae long and thin (0) or short, wide, and only slightly inclined (1).

108. Neural spines of dorsal vertebrae not expanded distally (0) or expanded to form "spine table" (1).

109. Scars for interspinous ligaments terminate at apex of neural spine in dorsal vertebrae (0) or terminate below apex of neural spine (1).

110. Number of sacral vertebrae: $5(0)$ or $6(1)$ or 7 or more (2).

111. Sacral vertebrae with unfused zygapophyses (0) or with fused zygapophyses forming a sinuous ridge in dorsal view (1).

112. Ventral surface of posterior sacral centra gently rounded, convex (0) or ventrally flattened, sometimes with shallow sulcus

(1) or centrum strongly constricted transversely, ventral surface keeled (2).

113. Pleurocoels absent on sacral vertebrae (0) or present on anterior sacrals only (1) or present on all sacrals (2).

114. Last sacral centrum with flat posterior articulation surface (0) or convex articulation surface (1).

115. Caudal vertebrae with distinct transition point (0) or without transition point (1).

116. Transition point in caudal series begins distal to the 10 th caudal (0) or between 7 th and 10 th caudal vertebra (1) or proximal to the 7 th caudal vertebra (2).

117. Anterior caudal centra tall, oval in cross section ( 0 ) or with box-like centra in caudals I-V (1) or anterior caudal centra laterally compressed with ventral keel (2).

118. Neural spines of caudal vertebrae simple, undivided $(0)$ or separated into anterior and posterior alae throughout much of caudal sequence (1).

119. Neural spines on distal caudals form a low ridge (0) or spine absent (1) or midline sulcus in center of neural arch (2).

120. Prezygapophyses of distal caudal vertebrae between $1 / 3$ and whole centrum length (0) or with extremely long extensions of the prezygapophyses (up to 10 vertebral segments long in some taxa) (1) or strongly reduced as in Archaeopteryx lithographica (2).

121. More than 30 caudal vertebrae (0) or 21-30 caudal vertebrae (1) or $<10$ caudal vertebrae, followed by pygostyle (2) or $11-20$ vertebrae (3).

122. Proximal end of chevrons of proximal caudals short anteroposteriorly, shaft proximodistally elongate (0) or proximal end elongate anteroposteriorly, flattened and platelike (1).

123. Distal caudal chevrons are simple (0) or anteriorly bifurcate (1) or bifurcate at both ends (2).

124. Shaft of cervical ribs slender and longer than vertebra to which they articulate (0) or broad and shorter than vertebra (1).

125. Ossified uncinate processes absent (0) or present (1).

126. Ossified ventral rib segments absent (0) or present (1).

127. Lateral gastral segment shorter than medial one in each arch (0) or distal segment longer than proximal segment (1).

128. Ossified sternal plates separate in adults (0) or fused (1).

129. Sternum without distinct lateral xiphoid process posterior to costal margin (0) or with lateral xiphoid process (1).

130. Anterior edge of sternum grooved for reception of coracoids ( 0$)$ or sternum without grooves (1).

131. Articular facet of coracoid on sternum (conditions may be determined by the articular facet on coracoid in taxa without ossified sternum): anterolateral or more lateral than anterior (0); almost anterior (1).

132. Hypocleidium on furcula absent (0) or present (1).

133. Acromion margin of scapula continuous with blade (0) or anterior edge laterally everted (1).

134. Anterior surface of coracoid ventral to glenoid fossa unexpanded (0) or anterior edge of coracoid expanded, forms triangular subglenoid fossa bounded laterally by coracoid tuber (1). 
135. Scapula and coracoid separate (0) or fused into scapulacoracoid (1).

136. Coracoid in lateral view subcircular, with shallow ventral blade (0) or subquadrangular with extensive ventral blade (1) or shallow ventral blade with elongate posteroventral process (2) or subtriangular (proximal end constricted, distal end wide) (3). 137. Scapula and coracoid form a continuous arc in posterior and anterior views $(0)$ or coracoid inflected medially, scapulocoracoid "L" shaped in lateral view (1).

138. Glenoid fossa without (0) or with extension of glenoid floor onto external surface of scapula (the surface opposite the costal surface) (1).

139. Scapula longer than humerus (0) or humerus longer than scapula (1).

140. Deltopectoral crest large and distinct, proximal end of humerus quadrangular in anterior view (0) or deltopectoral crest less pronounced, forming an arc rather than being quadrangular (1) or deltopectoral crest very weakly developed, proximal end of humerus with rounded edges (2) or deltopectoral crest extremely long (3) or proximal end of humerus extremely broad, triangular in anterior view (4).

141. Anterior surface of deltopectoral crest smooth (0) or with distinct groove or ridge near lateral edge along distal end of crest (1).

142. Olecranon process weakly developed (0) or distinct and large but not hypertrophied (1) or hypertrophied (2).

143. Distal articular surface of ulna flat (0) or convex, semilunate surface (1).

144. Proximal surface of ulna a single continuous articular facet (0) or divided into two distinct fossae separated by a median ridge (1).

145. Lateral proximal carpal (ulnare?) quadrangular (0) or triangular in proximal view (1).

146. Two distal carpals in contact with metacarpals, one covering the base of metacarpal I (and perhaps contacting metacarpal II) the other covering the base of metacarpal II (distal carpals 1 and 2 unfused) (0) or a single distal carpal capping metacarpals I and II (distal carpals 1 and 2 fused) (1).

147. Distal carpals not fused to metacarpals (0) or fused to metacarpals, forming carpometacarpus (1).

148. Distal carpals $1+2$ well developed, covering all of proximal ends of metacarpals I and II (0) or small, cover about half of base of metacarpals I and II (1) or cover bases of all metacarpals (2).

149. Metacarpal I half or less than half the length of metacarpal II, and longer proximodistally than wide transversely (0) or subequal in length to metacarpal II (1) or very short and wider transversely than long proximodistally (2).

150. Third manual digit present, phalanges present (0) or reduced to no more than metacarpal splint (1).

151. Flexor tubercles of manual unguals proximal (0) or displaced distally from articular end (1) or proximodistally elongated with proximal end close to articular facet (2).

152. Unguals on all digits generally similar in size (0) or digit I bearing large ungual and unguals of other digits distinctly smaller (1).

153. Proximodorsal "lip" on first manual ungual - a transverse ridge immediately dorsal to the articulating surface - absent (0) or present (1).

154. Ventral edge of anterior ala of ilium straight or gently curved (0) or ventral edge hooked anteriorly (1) or very strongly hooked (2).

155. Preacetabular part of ilium roughly as long as postacetabular part of ilium (0) or preacetabular portion of ilium markedly longer (more than $2 / 3$ of total ilium length) than postacetabular part (1).

156. Anterior end of ilium gently rounded or straight (0) or anterior end strongly curved (1) or pointed at anterodorsal corner (2). 
157. Supraacetabular crest on ilium as a separate process from antitrochanter, forms "hood" over femoral head present (0) reduced, not forming hood (1) or absent (2).

158. Postacetabular ala of ilium in lateral view squared (0) or acuminate (1).

159. Postacetabular blades of ilia in dorsal view parallel (0) or diverge posteriorly (1).

160. Tuber along dorsal edge of ilium, dorsal or slightly posterior to acetabulum absent (0) or present (1).

161. Brevis fossa shelf-like (0) or deeply concave with lateral overhang (1). 162. Antitrochanter posterior to acetabulum absent or poorly developed (0) or prominent (1).

163. Ridge bordering cuppedicus fossa extends far posteriorly and is confluent or almost confluent with acetabular rim (0) or ridge terminates rostral to acetabulum or curves ventrally onto anterior end of pubic peduncle (1).

164. Cuppedicus fossa deep, ventrally concave (0) or fossa shallow or flat, with no lateral overhang (1) or absent (2).

165. Posterior edge of ischium without (0) or with prominent proximodorsal prong (1).

166. Shaft of ischium straight in lateral view (0) or ventrodistal end curved anteriorly (1) or curved dorsally (posterodorsally concave) (2).

167. Obturator process of ischium absent (0) or proximal in position (1) or distally displaced (2).

168. Obturator process does not contact pubis (0) or contacts pubis (1).

169. Length of pubic boot_30\% length of pubis (0) or_40\% (1).

170. Semicircular scar on posterior part of the proximal end of the ischium, absent (0) or present (1).

171. Ischium more than $70 \%(0)$ or $70 \%$ or less of pubis length (1).

172. Distal ends of ischia form symphysis (0) or approach one another but do not form symphysis (1) or widely separated (2).

173. Ischial boot (expanded distal end) present (0) or absent (1).

174. Tubercle on anterior edge of ischium absent (0) or present (1).

175. Pubis propubic (0) or pubis vertical (1) or pubis moderately posteriorly oriented (2) or pubis fully posteriorly oriented (opisthopubic) (3).

176. Pubic boot projects anteriorly and posteriorly (0) or with little or no anterior process (1) or no anteroposterior projections (2). 177. Shelf on pubic shaft proximal to symphysis ("pubic apron") extends medially from middle of cylindrical pubic shaft (0) or shelf extends medially from anterior edge of anteroposteriorly flattened shaft (1).

178. Pubic shaft straight (0) or distal end curves anteriorly, anterior surface of shaft concave in lateral view (1) or anterior surface of shaft convex in lateral view (2).

179. Pubic apron about half of pubic shaft length (0) or less than $1 / 3$ of shaft length (1).

180. Femoral head without fovea capitalis (for attachment of capital ligament) (0) or circular fovea present in center of medial surface of head (1).

181. Lesser and greater trochanters unfused (0) or fused (1).

182. Lesser trochanter of femur alariform (0) or cylindrical in cross section (1).

183. Posterior trochanter absent or represented only by rugose area $(0)$ or posterior trochanter distinctly raised from shaft, moundlike (1).

184. Fourth trochanter on femur present (0) or absent (1).

185. Accessory trochanteric crest distal to lesser trochanter absent (0) or present (1).

186. Anterior surface of femur proximal to medial distal condyle without longitudinal crest $(0)$ or crest present extending proximally from medial condyle on anterior surface of shaft (1). 
187. Popliteal fossa on distal end of femur open distally (0) or closed off distally by contact between distal condyles (1).

188. Fibula reaches proximal tarsals (0) or short, tapering distally, and not in contact with proximal tarsals (1).

189. Medial surface of proximal end of fibula concave along long axis (0) or flat (1).

190. Deep oval fossa on medial surface of fibula near proximal end absent (0) or present (1).

191. Distal end of tibia and astragalus without distinct condyles (0) or with distinct condyles separated by prominent tendinal groove on anterior surface (1).

192. Medial cnemial crest absent (0) or present on proximal end of tibia (1).

193. Ascending process of the astragalus tall and broad, covering most of anterior surface of distal end of tibia (0) or process short and slender, covering only lateral half of anterior surface of tibia (1) or ascending process tall with medial notch that restricts it to lateral side of anterior face of distal tibia (2).

194. Ascending process of astragalus confluent with condylar portion (0) or separated by transverse groove or fossa across base (1).

195. Astragalus and calcaneum separate from tibia (0) or fused to each other and to the tibia in late ontogeny (1).

196. Distal tarsals separate, not fused to metatarsals (0) or form metatarsal cap with intercondylar prominence that fuses to metatarsal early in postnatal ontogeny (1).

197. Metatarsals not co-ossified (0) or co-ossification of metatarsals begins proximally (1) or distally (2).

198. Distal end of metatarsal II smooth, not ginglymoid (0) or with developed ginglymous (1).

199. Distal end of metatarsal III smooth, not ginglymoid (0) or with developed ginglymous delimited proximally by a ridge (1) or with a poorly developed ginglymous with proximal ridge absent (2).

200. In anterior view, metatarsal III not pinched (0) or pinched proximally (1) or pinched both proximally and through midshaft (2).

201. Ungual of pedal digit II similar in size to that of III (0) or pedal ungual II about $50 \%$ larger than pedal ungual III (1).

202. Metatarsal I articulates at middle of metatarsal II (0) or metatarsal I attaches to distal quarter of metatarsal II (1) or metatarsal I articulates with metatarsal II near its proximal end (2) or metatarsal I absent (3).

203. Metatarsal I attenuates proximally (0) or proximal end of metatarsal I similar to that of metatarsals II-IV (1).

204. Shaft of MT IV round or thicker dorsoventrally than wide in cross section (0) or shaft of MT IV mediolaterally widened and flat in cross section (1).

205. Foot symmetrical (0) or asymmetrical with slender MTII and very robust MT IV (1).

206. Neural spines on posterior dorsal vertebrae in lateral view rectangular or square (0) or anteroposteriorly expanded distally, fanshaped (1).

207. Shaft diameter of phalanx I-1 less (0) or greater (1) than shaft diameter of radius.

208. Angular exposed almost to end of mandible in lateral view, reaches or almost reaches articular (0) or excluded from posterior end angular suture turns ventrally and meets ventral border of mandible rostral to glenoid (1).

209. Laterally inclined flange along dorsal edge of surangular for articulation with lateral process of lateral quadrate condyle absent (0) or present (1).

210. Distal articular ends of metacarpals I + II ginglymoid (0) or rounded, smooth (1)

211. Radius and ulna well separated (0) or with distinct adherence or syndesmosis distally (1).

212. Kink and downward deflection in dentary buccal margin at rostral end of dentary: absent (0) or present (1).

213. Quadrate head covered by squamosal in lateral view (0) or quadrate cotyle of squamosal open laterally exposing quadrate head (1). 
214. Brevis fossa poorly developed adjacent to ischial peduncle and without lateral overhang, medial edge of brevis fossa visible in lateral view (0), or fossa well developed along full length of postacetabular blade, lateral overhang extends along full length of fossa, medial edge completely covered in lateral view (1).

215. Vertical ridge on lesser trochanter present (0) or absent (1).

216. Supratemporal fenestra bounded laterally and posteriorly by the squamosal ( 0$)$ or supratemporal fenestra extended as a fossa on to the dorsal surface of the squamosal (1).

217. Dentary fully toothed (0) or only with teeth rostrally (1) or edentulous (2).

218. Posterior edge of coracoid not or shallowly indented below glenoid (0), or posterior edge of coracoid deely notched just ventral to glenoid, glenoid lip everted (1).

219. Retroarticular process points caudally (0) or curves gently dorsocaudally (1).

220. Flange on supraglenoid buttress on scapula absent (0) or present (1).

221. Depression (possibly pneumatic) on ventral surface of postorbital process of laterosphenoid absent (0) or present (1).

222. Basal tubera set far apart, level with or beyond lateral edge of occipital condyle and/or foramen magnum (may connected by a web of bone or separated by a large notch) (0) or tubera small, directly below condyle and foramen magnum, and separated by a narrow notch (1).

223. Basioccipital without pneumatization on occipital surface (0) or with subcondylar recess (1).

224. Ventral surface of dentary straight or nearly straight (0) or descends strongly posteriorly (1).

225. Distal humerus with small or no medial epicondyle $(0)$ or with large medial epicondyle, medial condyle centered on distal end (1).

226. Distal humeral condyles on distal end (0) or on anterior surface (1).

227. Ilium and ischium articulation flat or slightly concavo-convex (0) or ilium with process projecting into socket in ischium (1).

228. Roots of dentary and maxillary teeth mediolaterally compressed (0) or circular in cross-section (1).

229. Preacetabular portion of ilium parasagital (0) moderately laterally flaring (1) strongly laterally flaring (2).

230. Maxillary and dentary teeth labiolingually flattened and recurved, with crowns in middle of tooth row more than twice as high as the basal mesiolateral width (0) or lanceolate and subsymmetrical (1) or conical (2) or labiolingually flattened and recurved, with crowns in middle of tooth row less than twice as high as the basal mesiolateral width (fore-aft basal length) (3).

231. Dentary teeth do not (0) or do increase in size anteriorly, becoming more conical in shape (1).

232. Length of skull more than $90 \%$ femoral length (0) or less than $80 \%$ (1).

233. Height of skull (minus mandible) at middle of naris more than half the height of skull at middle of orbit (0) or less than half (1).

234. Dorsal margin of naris below level of dorsal margin of orbit (0) or above (1). 235. Snout does not (0) or does taper to an anterior point (1).

236. Area of antorbital fenestra greater than that of orbit (0) or less than that of orbit (1).

237. Body of premaxilla dorsoventrally deep (0) or dorsoventrally shallow (1).

238. Antorbital fossa anteriorly bounded by maxilla (0) or by premaxilla (1).

239. Maxillary antorbital fossa: small, from $10 \%$ to less than $40 \%$ of the rostrocaudal length of the antorbital cavity (0), large, greater than $40 \%$ of the rostrocaudal length of the antorbital cavity (1).

240. Maxillary fenestra large and round (0), a large, craniocaudally elongate oblong (1), a small, craniocaudally elongate slit, not dorsally displaced (2), or a small, dorsally displaced opening (3). 
241. Nasal fusion: absent, nasals separate (0) or present, nasals fused together (1). 242. Nasal surface: smooth (0) or rugose (1). 243. Suborbital process of jugal short and dorsoventrally stout (0) or elongate and dorsoventrally narrow (1).

244. Nasals at least as long as frontals (0) or shorter than frontals (1).

245. Anterior upturning of nasals absent (0) or present (1).

246. Jugo-maxillary bar at ventral end of antorbital fenestra dorsoventrally deep (0) or dorsoventrally narrow (1).

247. Anteroventral corner of premaxilla does not (0) or does form an acute, ventrally orientated point in lateral view (1).

248. Length of preorbital region of cranium $>$ height at anterior edge of preorbital bar (exclusive of midline sagittal ridge, if any) (0) or_height at anterior edge of preorbital bar (1).

249. Frontals without supraorbital rim (0) or with supraorbital rim (1).

250. Parietals shorter than frontals (0) or longer (1).

251. Length of ventral border of infratemporal fenestra comparable to that of orbit (0) or much shorter (1).

252. Foramen magnum smaller than or subequal to size of occipital condyle (0) or larger than occipital condyle (1).

253. Dentary not bowed (0) or bowed (concave dorsally) (1).

254. Meckelian groove of dentary deep (0) or shallow (1).

255. Dentary without posteroventral process extending to posterior end of external mandibular fenestra (0) or with such a process (1).

256. Horizontal shelf on the lateral surface of the surangular, rostral and ventral to the mandibular condyle: absent or faint ridge (0), prominent and extending laterally (1).

257. Premaxillary teeth subequal in size to (0) or much smaller than (1) the maxillary teeth.

258. Approximately the same number of denticles per $5 \mathrm{~mm}$ on mesial keels of teeth as on distal keels (0) or markedly more denticles per $5 \mathrm{~mm}$ on mesial keels (1).

259. Maxillary teeth subperpendicular to ventral margin of maxilla (0) or strongly inclined (1).

260. Dentary tooth implantation: in sockets (0), in paradental groove (1).

261. Dentary dentition continues cranially to tip of dentary (0) or terminates before reaching dentary tip (1).

262. Length of mid-cervical centra approximately the same as dorsal centra (0) or markedly longer than dorsal centra (1).

263. Cervical prezygapophyses unflexed (0) or flexed (1).

264. Dorsal centra_1.2 $\times$ taller than long (0) or height_length (1).

265. Posterior dorsal neural spines_1.5 $\times$ taller than long $(0)$ or height $<1.5 \times$ length (1).

266. Postzygapophyses of middle and posterior dorsal vertebrae do not extend posterior to centrum (0) or do (1).

267. Anteriormost haemal arches_1.5 $\times$ longer than associated centra $(0)$ or $<1.5 \times$ as long as centra (1).

268. Angle between furcular arms $>80_{-}(0)$ or $<60_{-}(1)$.

269. Acromion process contacts coracoid (0), or reduced and does not contact coracoid (1).

270. Acromion process does not match any of the following descriptions: (0) rectangular with its dorsal edge forming a 90 angle with the dorsal edge of the scapular blade (1) or a quarter-circle in shape (2) or triangular, with apex pointing away from and subparallel to scapular blade (3).

271. Scapulocoracoid dorsal margin: pronounced notch between the acromion process and the coracoid (0) or margin smooth (1).

272. Wide distal expansion of scapula absent (0) or present (1).

273. Acrocoracoid process absent (0) or present (1).

274. Humeral length is half femoral length or less (0) or shorter than femur but more than half femoral length (1) or longer than femur (2). 
275. Length of humeral shaft between deltopectoral crest and distal condyles $<4.5 \times$ shaft diameter $(0)$ or $>4.5 \times$ shaft diameter (1).

276. Ulna not bowed away from humerus (0), or bowed away from humerus (1).

277. Length of radius $<1 / 3$ femoral length ( 0 ) or between $1 / 3$ and $2 / 3$ femoral length (1).

or between $2 / 3$ and $1 \times$ femoral length (2) or $>$ femoral length (3).

278. Radial diameter $>0.5 \times$ ulnardiameter $(0)$ or_ $0.5 \times(1)$.

279. Distal carpals $1+2$ flattish (0) or semilunate in shape (1).

280. Length of manual digit II (including metacarpal) less than $1.25 \times$ femoral length $(0)$ or_1.25 $\times$ femoral length (1).

281. Distal end of metacarpal I medially (0) or laterally rotated (1).

282. Medial side of metacarpal II: expanded proximally (0), not expanded (1).

283. Metacarpal III $>0.8 \times$ length of metacarpal II $(0)$ or $<0.8 \times(1)$.

284. Manual phalanx I-1 longer than metacarpal II (0) or shorter (1) (Pérez-Moreno et al. 1994).

285. Length of metacarpal II < length of metacarpal I + phalanx I-1 (0) or_(1).

286. Metacarpals II and III are not (0) or are appressed for their entire lengths (1).

287. Proximal end of metacarpal III is not (0) or is mainly palmar to that of metacarpal II (1).

288. Length of manual phalanx II- $2<1.2 \times$ length of phalanx II-1 (0) or $>1.2 \times(1)$.

289. Medial ligament pits of manual phalanges deep (0) or shallow (1).

290. Posterior flange on manual phalanx II-1 absent (0) or present (1).

291. Combined lengths of manual phalanges II-1 and II-2 > length of metacarpal II + carpus (0) or_length of metacarpal II + carpus (1).

292. Length ofmanual phalanx II-1 < $2 \times$ length of III-1 (0) or_ $2 \times$ length of III-1 (1).

293. Length of manual phalanx II- $2<2 \times$ length of II-1 (0) or_ $2 \times(1)$.

294. Length of manual phalanx III-1 $<2 \times$ length of phalanx III-2 (0) or $>2 \times(1)$.

295. Manual phalanx I-1 straight (0) or bowed (palmar surface concave) (1).

296. With proximal articular surface of ungual orientated vertically, dorsal surface of manual ungual I does not (0) or does arch higher than level of dorsal extremity of proximal articular surface (1).

297. With proximal articular surface of ungual orientated vertically, dorsal surface of manual ungual II does not (0) or does arch higher than level of dorsal extremity of proximal articular surface (1).

298. Manual ungual I strongly curved (0), weakly curved (1), or straight (2).

299. Manual unguals II and III strongly curved (0), weakly curved, (1), or straight (2).

300. Proximodorsal "lip" on manual unguals II and III absent (0) or present (1).

301. Manual digit III with four phalanges (0) or less than four phalanges (1).

302. Manual phalanx III-3 markedly shorter than combined lengths of phalanges III-1 and III-2 (0), subequal in length to their combined lengths (1), or markedly longer (2).

303. Arching of preacetabular iliac blade above height of postacetabular blade absent or small (0) or extreme (1).

304. Shaft of ischium subequal in thickness to the pubis (0), slenderer than the pubic shaft (1), thicker than the pubic shaft (2).

305. Obturator process does not (0) or does form a strongly acute angle in lateral view (1).

306. Obturator process does not (0) or does reach tip of ischium (1).

307. Ventral notch between the distal portion of the obturator process and the shaft of the ischium: present (0), absent (1). 
308. Strong kink of pubis at midshaft absent (0) or present, displacing distal half of pubis caudally (1).

309. In adult, femur longer than tibia (0) or shorter (1).

310. Tip of lesser trochanter below level of femoral head (0) or level with femoral head (1).

311. Proximolateral (fibular) condyle of the tibia, development in proximal view: bulge from the main surface of the tibia (0), conspicuous narrowing between the body of the condyle and the main body of the tibia (1).

312. Metatarsus less than half length of femur (0) or more than half femoral length (1).

313. Metatarsal cross-sectional proportions: subequal or wider mediolaterally than craniocaudally at midshaft (0), deeper craniocaudally than mediolaterally at midshaft (1).

314. Shafts of metatarsals not appressed (0) or appressed (1). 315. Length of metatarsal V_0.5× length of metatarsal IV (0) or $<0.5 \times(1) .316$. Marked decrease in transverse width of metatarsus distally, absent (0) or present (1).

317. Plantar surface of hallux faces posteriorly (0) or hallux reorientated so that plantar surface faces medially or anteriorly (1).

318. Hallucal ungual reduced in size relative to other pedal unguals (0) or not reduced (1).

319. Hallucal ungual weakly curved (0) or strongly curved (1).

320. Length of pedal phalanx II-2 between $0.6 \times$ and $1 \times$ length of phalanx II-1 (0),_0.6 × or (1)_1× (2).

321. Total length of pedal phalanx II-2 (not counting posteroventral lip, if any) $>2 \times$ length of distal condylar eminence ( 0 ) or $2 \times(1)$.

322. Pedal phalanx II-2 without posteroventral lip or keel (0) with transversely wide posteroventral lip (1) with transversely narrow posteroventral keel (2).

323. Pedal phalanx II-1 without dorsal extension of distal condyles (0) or with extension (1).

324. Pedal unguals III and IV straight or weakly curved (0), or strongly curved (1).

325. With fingers extended, tip of ungual III extends no further distally than flexor tubercle of ungual II (0) or extends further (1).

326. Manual ungual III smaller than ungual II (0) or approximately the same size (1).

327. Diameter of non-ungual phalanges of manual digit III $>0.5 \times$ diameter of non-ungual phalanges of digit II (0) or $<0.5 \times(1)$.

328. Manual phalanx II-1 shorter than I-1 (0) or longer (1).

329. Ischial shaft rod-like (0) or flat, plate-like (1).

330. Lateral face of ischial shaft flat (or round in rodlike ischia) (0) or laterally concave (1) or with longitudinal ridge dividing lateral surface into anterior and posterior parts (2).

331. Contact between pubic apron contributions of both pubes meet extensively (0) or contact interrupted by a slit (1) or no contact (2).

332. Dorsal margin of postacetabular iliac blade straight or convex (0) or concave (1).

333. Large, longitudinal flange along caudal or lateral face of metatarsal IV absent (0) or present (1).

334. Distally placed dorsal process along caudal edge of ischial shaft absent (0) or present (1).

335. Length of metatarsus $<3.5 \times$ transverse midshaft diameter $(0)$ or $3.5-8 \times$ midshaft diameter (1) or $>8 \times$ midshaft diameter (2).

336. Lengths of mid-caudal centra subequal to or less than those of proximal caudal centra (0) or_twice as long as proximal caudal centra (1).

337. Pubic peduncle of ilium craniocaudally longer (0) or shorter (1) than ischial peduncle of ilium.

338. Phalanges of pedal digit III not blocky (proximal phalanx length_ $2 \times$ diameter) $(0)$ or blocky (proximal phalanx length $<2 \times$ diameter) (1). 
339. Width of distal humeral expansion $<1 / 3$ humeral length $(0)$ or_1/3 humeral length (1).

340. Lateral epicondyle of humerus not expanded laterally (0) or expanded laterally (1).

341. Distal end of metatarsal I reduced in size relative to distal ends of other metatarsals (0) or comparable in size to distal ends of other metatarsals (1).

342. Pedal phalanx II-1 longer (0) or shorter (1) than pedal phalanx IV-1.

343. Dentary ramus elongate (0) or shortened, not much longer than tall (1).

344. Metacarpal II_1/3 humeral length $(0)$ or $<1 / 3$ humeral length (1).

345. With fingers extended, tip of ungual I does not extend past flexor tubercle of ungual II (0) or extends past flexor tubercle of ungual II but does not extend past tip of ungual II (1) or extends past tip of ungual II (2).

346. Premaxillary teeth serrated (0) or unserrated (1).

347. Sublacrimal process of jugal dorsoventrally expanded (taller than suborbital bar of jugal) (0) or not dorsoventrally expanded (1).

348. Flexor tubercles of manual unguals_ $1 / 3 \times$ height of articular facet $(0)$ or $<1 / 3(1)$.

349. Distal chevrons straight or L-shaped in lateral view (0) or upside-down T-shaped (1).

350. Metacarpal III distally not ginglymoid (0) or ginglymoid (1).

351. Breadth of acromion process perpendicular to long axis of scapular blade: deep (0) or shallow (1).

352. Proximal end of metatarsal IV curls around plantar side of proximal end of metatarsal III (0) or does not (1).

353. Midsagittal ridge formed by dorsal displacement of midline of frontals, nasals and premaxillae, absent (0) or present (1).

354. Ectopterygoid lateral to pterygoid (0) or rostral to pterygoid (1).

355. Palatine-pterygoid-ectopterygoid bar does not (0) or does (1) arch below ventral cheek margin. 356. Co-ossification of angular and surangular absent (0) or present (1).

357. Cervical ribs unfused to cervical vertebrae (0) or fused to cervical vertebrae (1).

358. Anteroproximal contact between metatarsals II and IV absent (0) or present (1).

359. Anterior caudal vertebrae without pneumatopores (0) or with pneumatopores (1).

360. External mandibular fenestra not rostrally displaced (sits beneath orbit) (0) or rostrally displaced (sits largely anterior to orbit) (1).

361. Ilium, pubic peduncle: substantially larger than (0) or subequal to (1) ischial peduncle 362 . Ischium, length relative to pubis: shorter (0) or longer (1).

363. Ischium, shape: distally narrower (0) or distally wider (1) (excluding obturator process).

\section{Newly AdDed Characters}

364. Rostral portion of the maxilla elongate: absent (0), present (skull length exceeding femoral length more than 25\%) (1). (Novas et al. 2009).

365. Maxilla with postantral wall enlarged: absent (0), present and postantral wall backwardly expanded (1). (Novas et al. 2009).

366. Teeth with longitudinal grooves and ridges: absent (0), present (1). (Gianechini et al. 2009). 


\section{APPENDIX II - Data matrix}

Allosaurus fragilis

?11000?0000000000010001000100000011101100201?2000000000000010000000000000010000000000101010010000000100 $100000000001 ? 01000000001 ? ? ? ? 000000000010001010001010000001000001010000000000000001100000010000000000000$ 000000100000000000000000000000000000000000000000010000000000000000000000000000000000100000000000000000 $000000000000000000000000000000000000000000000000000000[12] 00000$

\section{Sinraptor}

?11000??00?00000001000100010?00000010110020102?00000000000010000?00000000?10?000000001010100100000001001 00000000001?0?????????1?00?0?0??00?????????00??10000?0100?001000000001000000001100000010000000000000?100 ?000?00?000000??0000000000000000000000000000010000000100??00?0???????0?00??00?0????????00???02000000000010 ?0000000??0?0000000?00??000??001?0000000000000000000

Dilong paradoxus

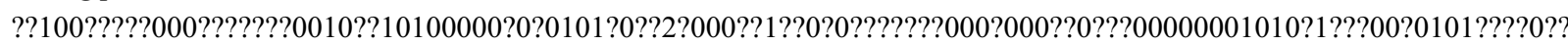

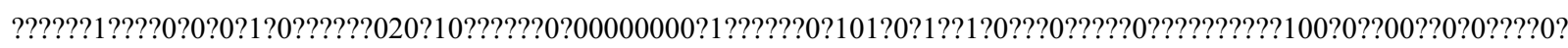
0????0???0?0000000001310000000000?0???110?0001100?0001011?1??00?10000100010000000001?0001010?10110000000 000010???0?01?00??0?0?0000100?0???000000000000

Eotyrannus lengi

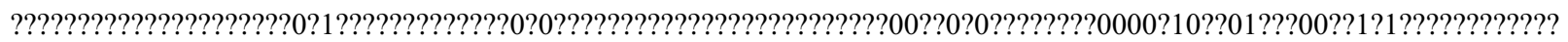

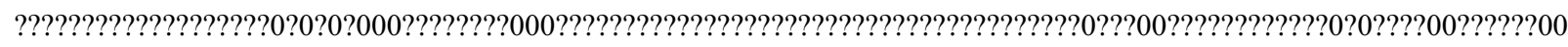

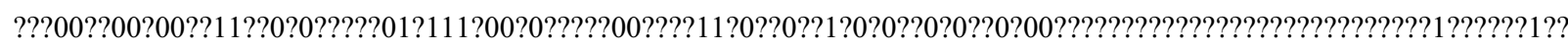
000??0?00?0???00??????????????0

\section{Tyrannosaurus rex}

?10000?00?00000002100001101010000000001012010211000010010001?00000000000001001000000010101101000000010 0101000000101?00000000??1????0000000010100??0?010001001000100000101101101000000000100001000100000200000 $001000000000000001000100000000000101100000000000101100000000000010100000 ? 001110001000 ? 0 ? 00 ? 0 ? ? ? ? 0100100$ 1010110?0000000???000100000000000010000100000000100000200000

Gorgosaurus libratus

?10000?00?000?0???10000110111000000001101201?21100?010010001????00000000001001000000010101101000000??00 $101000000101 ? 00000000001 ? ? ? ? 00000000101000001010001001000100000101100101000000000100001000100000200000$ $001000000000000 ? 0100010000000000010110000000000010110000000000001110000000 ? 01100101000 ? 0 ? 000000 ? ? 010010$ $0101011000000000 ? ? ? 00010001000000001000010000000010000000000$

\section{Tanycolagreus topwilsoni}

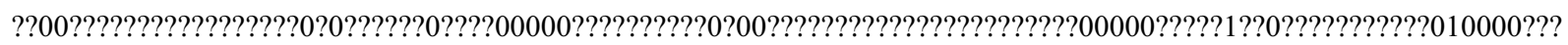

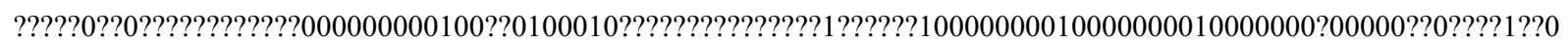
00????00???????0?0???00??0?0????????1??????110??0010011110000111000100010001000001?????010010110000000000 $011 ? ? 1 ? 0 ? 1 ? ? 00000 ? 00 ? ? 0 ? 000 ? ? ? ? ? 0 ? ? ? ? ? 00000$

Coelurus fragilis

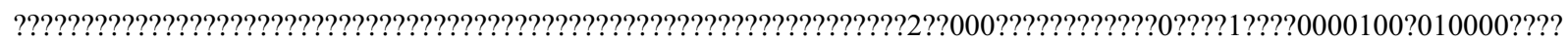

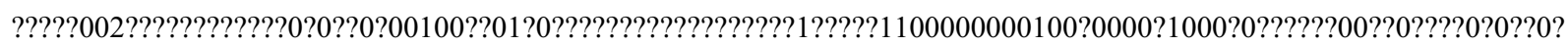

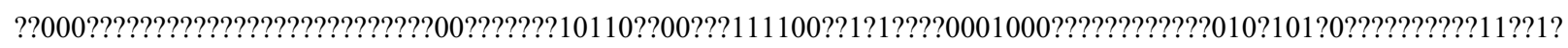
$0 ? 1 ? ? ? 00 ? ? 00 ? ? ? ? ? ? 00 ? ? ? ? 000 ? 00000000$

\section{Ornitholestes hermanni}

?0110???0?0?00?1???0?010?011100001?000000?00?100000001?01011?????00000000000?000000?0101000???00011?11011 0000??100??0010??1??????????????0?000??????00010001??010?0010?000101?10000001??0???????00000????00000?001 0?00?0?00?00010000100010010?01??1000?100?000?00001110??????11010?0????????0?????000100??010010?0?101?0???? ???0????000000100000??0??1101??00000000000000000 
Compsognathus longipes

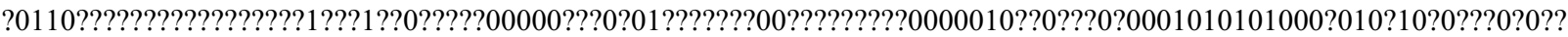

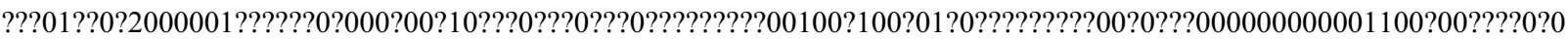

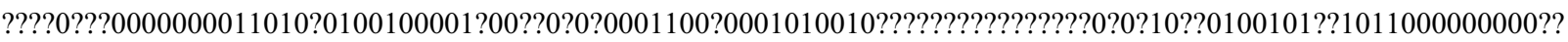
0?00?00010?000000??1110?000??0000000000001

Huaxiagnathus orientalis

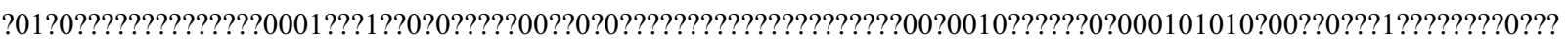

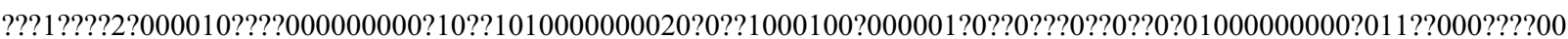
?0???0???0000000011010?0100100001?0???1?0?00011?0?0000010010000?00000100010?0000000?0100101??10110000000? $0001000 ? 00010000000000 ? 10000 ? 0 ? ? ? ? 00000000000$

\begin{abstract}
Sinosauropteryx prima

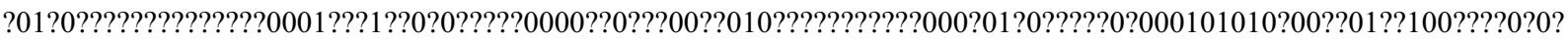
0????1??11200000100????00000?00?10??1010001000020??????00100?100?01?0??00?00?000?0?01000000000?011??0000?0 00000???0???000000001101000100100001?0???0?0?0001101?0001000000000?0000010001000000100001001010?1?110000 $000000 ? 10000 ? ? 010000000001110000 ? 0 ? ? ? 000000000000$
\end{abstract}

\begin{abstract}
Deinocheirus mirificus
?????????????????????????????????????????????????????????????????????????????????????????????????????????????????

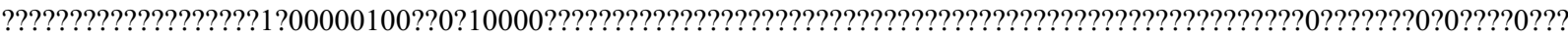
??????????????????????????????????????0?0??10?0??1100000100000000000001??????????????????????1100??????????0 $0 ? ? ? 11 ? ? 1$ 1?0??????????????????
\end{abstract}

\title{
Harpymimus okladnikovi
}

?011???????????????21000????000??????0000??00??????????????????020000?0000????1?122????0?0???00?110001?0000 $1 ? 10000$ ?00000?1????????0?0?0?00010010010020010??00011???0???????????00??????????????00000010??0000?10110???1 ?00???000?1?2011001101?00100?00101?00?0???0000110??00?0??10?00001000001000000000010020????0????01?0???0000 $0010000 ? 00 ? 120000 ? 0000 ? ? 110 ? 00 ? 0 ? 0000 ? ? ? 00000$

\section{Pelecanimimus polyodon}

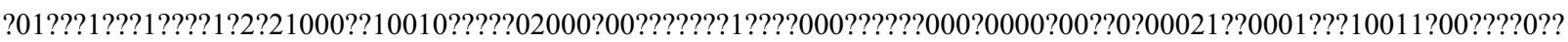
?????????????????0100???02???2?10??00110200?????????????????????????????????????????????????????001010????1?1?? ??0???1?10?1001100200100100101?0??00?010001????????0?10?00?1100011100001000012002??????????????????????1100? ??0?0???????011111?0??0?000??0???00000

\section{Shenzhousaurus orientalis}

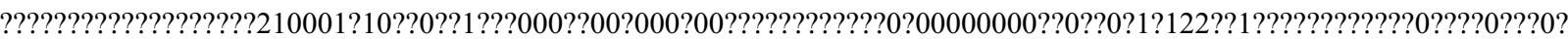
??00000???0??????????????????????????020010000??110?00100?000000100?0000110?????????????????0??1??120011????

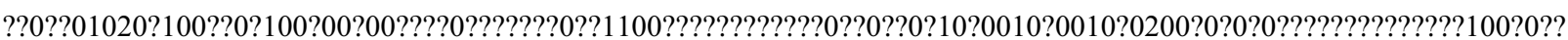
0?0?00?????0???11?0??0?0???0000000000

\section{Archaeornithomimus asiaticus}

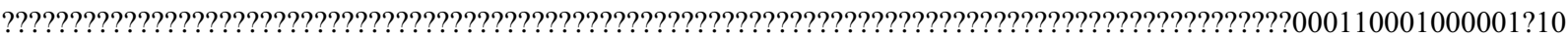
0000000?0?????????010201?20100??0?10100???000?1100011001?00?00100000001?00010001000001?3?0000??01??10??1? 1????000???????????????????????????????????1110??00??0?10?0??110?0001000?1??001200??00010100?1120?????????000 0?000100?00???11??1?001????010?00000000

\section{Garudimimus brevipes}

?0110????01101????021001101001000??002000000000010?1??0?0001??1??0000000000020001?1?3???????01100???000??0

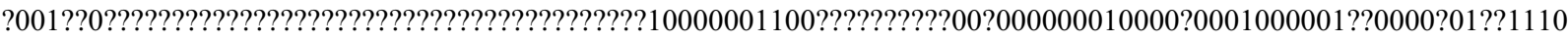
??11?0010????0??1100110120010010010100000?????11110???????????????????????????????????0????010110110010???00 ?????000?1000??000???1????00000000000000000 
Anserimimus planinychus

??????????????????????????????????????????????????????????????????????????????????????????????????????0??????????

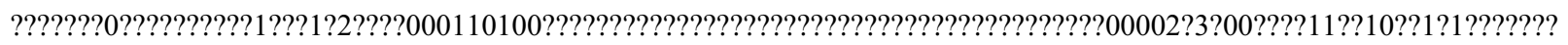
???????????????????????????????????????????1???0??0?1200011100010000022001??????????1100????????100??????2???0 $0 ? ? ? 11 ? ? 1$ ?0???????1?????00000

Ornithomimus edmontonicus

?01110?110?101?101021001101?0100211000000000000000010000000??????00000000010??001?1?3??????001?0011000010 000010100000000?001001?????011201020100000?101001000000110001100100000010000000110001000100000203?00001 11111101?11100?000??0??11011101200100100101?0?0??????1?1100?0011011010?01?0001110001100002200200001010?11 $1 ? 0 ? ? ? 10000110000 ? 000200000 ? 0011 ? 11100 ? ? 000010000000000$

\section{Struthiomimus altus}

?01110?110??0??101021001101?010021100000000000000001?0000001?01??0000000001020001?1?3??????001?1011000010 $0000101000000000001001 ? ? ? ? ? 0112010201000001101001000000110001100100000000000000110001000100000203 ? 00001$ $11111101 ? 111001000 ? ? 0 ? ? 1100110120010010010100 ? 10 ? ? ? ? ? 1111000001001101000110000110000100001100200001010 ? 1$ $1110 ? ? ? 10000110000 ? 000200000 ? 0011 ? 1110010 ? 000100 ? ? ? 00000$

\section{Gallimimus bullatus}

?01110?11011010101021001101?01002110000000000000000100000001?01010000000001020001?1?3??????0011001100001 000001?100000000000100??????0112010201000?01101001000000110001100100000010000000110001000100000203?00000 $11111101 ? 1110010000 ? 0 ? ? 1100110120010010010100000 ? ? ? ? ? 111100 ? 00 ? 00110100011000001000010000110020000101011$ 11?0???100001100000000200000?0011?1110010000010000000000

\section{Falcarius utahensis}

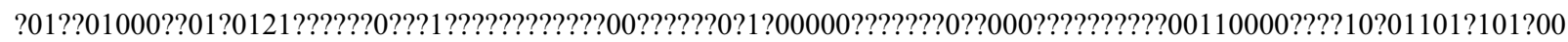
0?110011102?011?????????00?100011011?0000000100?11001010220001?10101000000010001001010000000?00000??0???1 0?00?0?0111111111???????????????????00?????0001?11???0?????11?01?0111000100010000000100021?101????0?0?0?00? 000010???000000000000?0??0?0??????00?00000000

\section{Beipiaosaurus inexpectus}

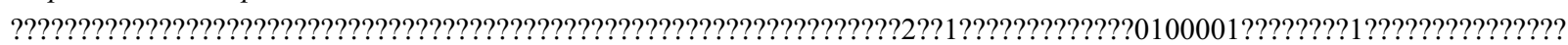

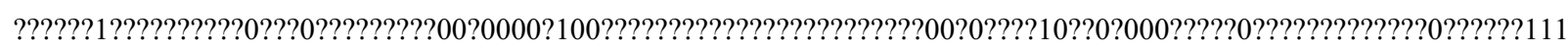

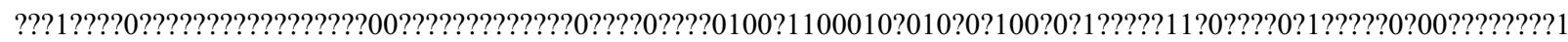
???0?0?0??0?0???????00?00000000

\section{Alxasaurus elesitaiensis}

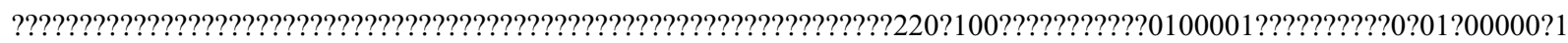

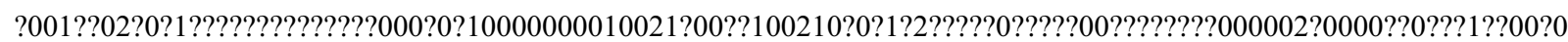

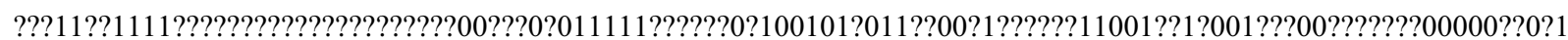
??000?010001?0????000???????0?00000000

\section{Nothronychus mckinleyi}

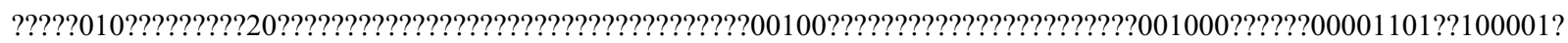

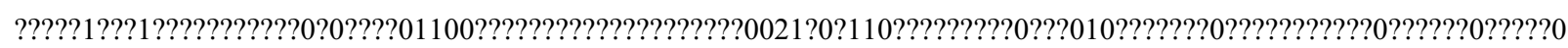

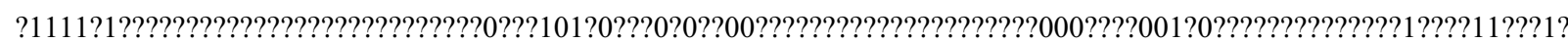
???00??????0????????0??????????

\section{Erliansaurus bellamanus}

????????????????????????????????????????????????????????????????????????????????????????????????????1???0?????????

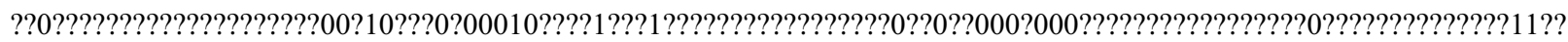
?????????????????????????????????????????0?10010?001110000101000011000019?????019?????????????0100????????1?0 0???00??0?1?????0????0??????? 


\begin{abstract}
Nanshiungosaurus brevispinus

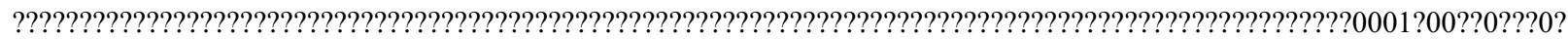

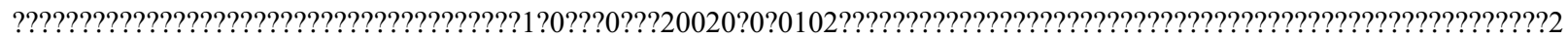

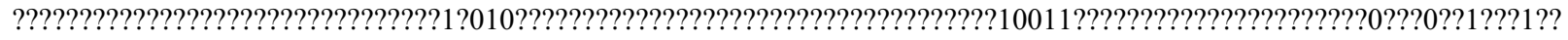
?????????????0???000?????
\end{abstract}

Neimongosaurus yangi

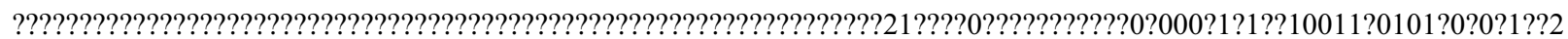
?01000210?1???????0001000000???????????1??21100??2???????????????00?00000???20??000000?20100?????0?1???0?0??

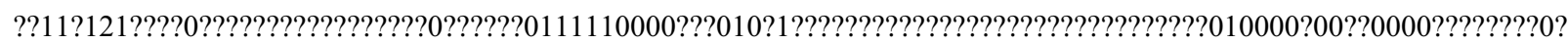
?001110100?????0?01????000?000?????

\title{
Segnosaurus galbiensis
}

?????????????????????????????????????????????????????????????????22?+10?00002000??20100001??????????????????????? 0?????????????????0?10?1200???????0???100211001?200210?0?1020?0???????200??0?00??0000?2120??00????1??0?0???? 111012111 ????????????????????00?????01???????021?0?0??0???????????????????????1000100??0?0100111??019??????001 ??11?01?0??????01?????0?0000?????

Erlikosaurus andrewsi

?0110??02?1?1?0???010011100??10001?100000100011000?0??00100??11112200100000020001?00100001?????????????????

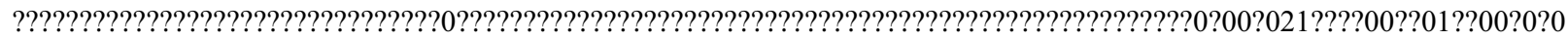
00111?1?11?0001001?001001000010000000001?????????????0???????????????????????????????????0?0?001100001??????? ???0??111100???1?????0100???0???00000

\section{Therizinosaurus cheloniformis}

????????????????????????????????????????????????????????????????????????????????????????????????????????????

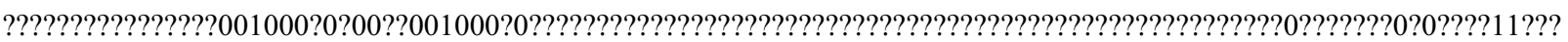

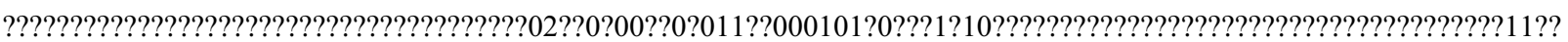
?0???0?10????????????????

\section{Patagonykus puertai}

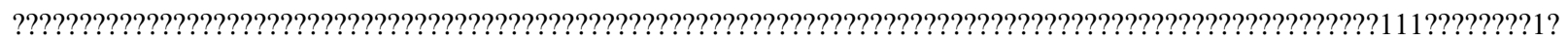

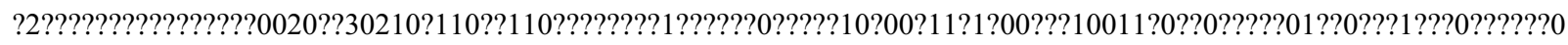

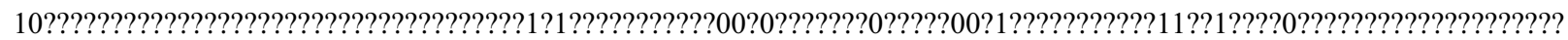
1???????1????????00?????????

Mononykus olecranus

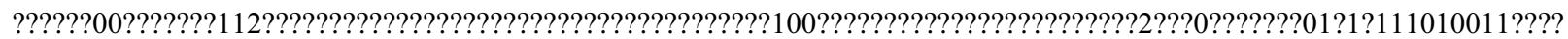
1??2??????1???1000?000200030210?1122?1100??1????1??000??????33?0?0110100111011211000020?00001??00???1??0?0

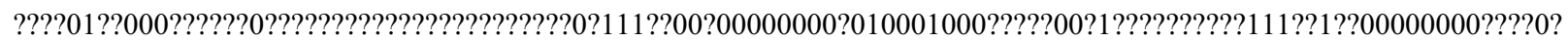
?00???001100?1???1?00?????010?00000000

\footnotetext{
Shuvuuia deserti

?0110100000000?112010000?00??00?111??000010000101010010010???1?110001000000021000?021??000??011111101110 1 1?0??1?201??2012000100?1000?00020?03021??1122011000?1?1011?2000?00021032?0??1101001110112110000201000?11 000001100000010001?1??0?100110??0010010010110?00??0?0???????001?00000??0???001?000??0?000110???0????1??111 ?000?0010011000?00002?001100012111101?0?0?010000000000

Protarchaeopteryx robusta ?????????????????????0???????????????????????????????????????????0??000???????202022??0002???200?1?????????????

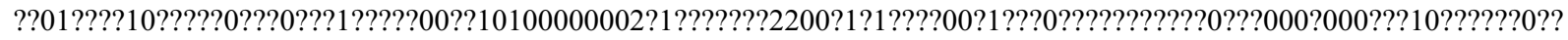

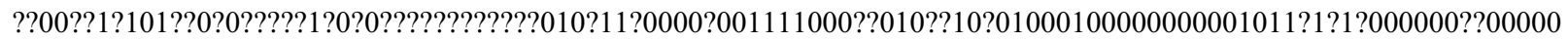
??0000100?000000011010?1???????000000000
} 
Elmisaurus rarus

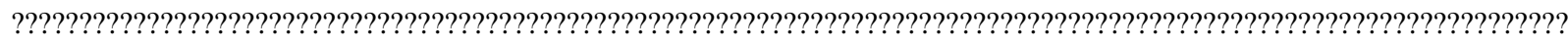

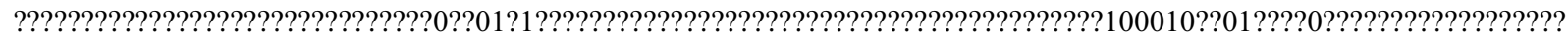

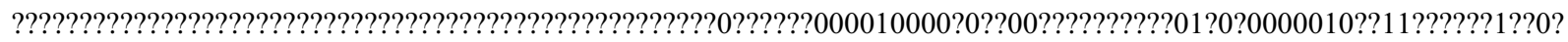
?00??0??1???1?????1?????????

Caenagnathus collinsi

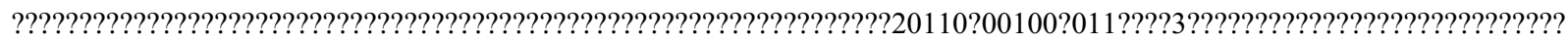

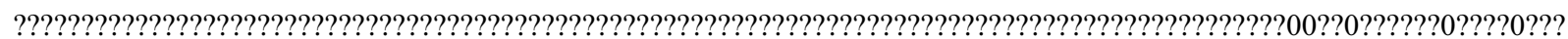
????????????????????????1?10??????????????????????????????????????????????????????????????????????????????????? $0 ? ? ? ? ? ? ? ? ? ? ? 0 ? ? ? 0 ? ? ? 0000 ?$

\section{Rinchenia mongoliensis}

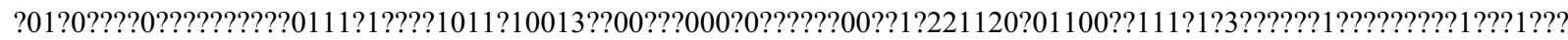

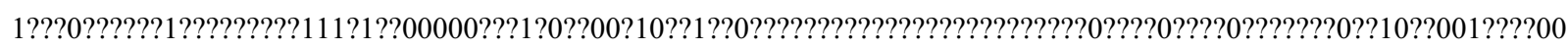
???0????????10101???01901110?010?10???????????????1??????????????????????????0??????1????????????????????? ????0?????1???1????11100?11???0000?

\section{Citipati osmolskae}

?011001001001??2210001111110001011?10013210001100000110011000110221120?0110010111?1?3??????101100110010 1111001??20???002100111?011111?010000100?11000001110021100?110220?0??1010010?1101000000100?0000010000000 100100110?000000000??0???01010110101001110101001??????10????010?0010110100101000000000000000100??????1??1 01?00000001011001000001??00000100?10?01?1110?0?10000000?

\section{Ingenia yanshini}

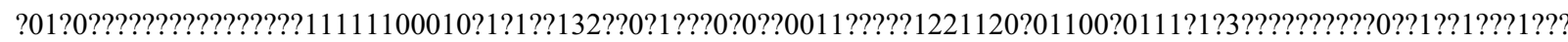
2???01????2100???0011111111?000000??10000010100211??11?022000011010?110110100000?100100000000000?1100?0? 11??000?0?0000?0??101010110?01?01110?010?10?????????0010?001011010010100000010000000110000001011?101?00? ????00100010000000000000101?101011011000110000000?

\section{Khaan mckennai}

?0110??????????????00111?110?01011?1001321000110?000??00110??????21120?01?00?0111??????????10110??1??101111 0??????1??00210?111001??111110000?00?1100000111002110?1110220001?101??1??110100?0??1001000000000000010010 0110?000???000??0??1010101101010011101010?10?????001110010?001011010010100000000000000110000001011?10110 $00000000100010000000000000100 ? 10101 ? 0 ? 1010110000000$ ?

\section{Heyuannia huangi}

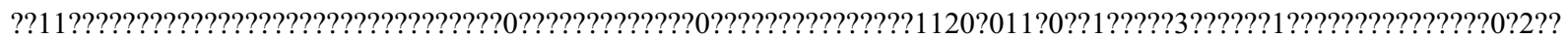

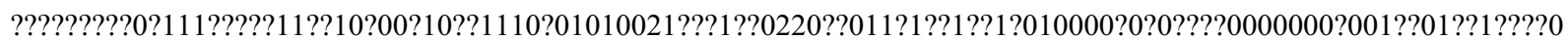

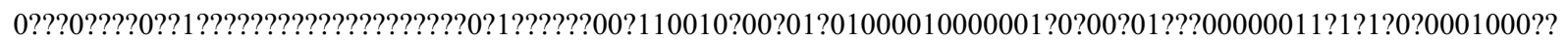
?010?0?00?0000001?1??0?01?0????01?000?????

\footnotetext{
Sinovenator changii

?0???1002?000011120000101?11100???1??????000011???011?10100??????000?001??????0000021??01??????1?111000110 100001000110????1?????????010111?0?????????000???21??0111002000111011100?11110000???00100010019?000?????0

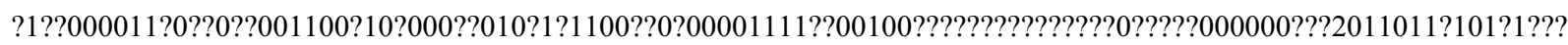
$0011 ? ? 0 ? ? 1000102 ? 00 ? ? 000 ? ? 1 ? 0 ? ? 110 ? ? ? 00 ? ? 00000000$

\section{Mei long}

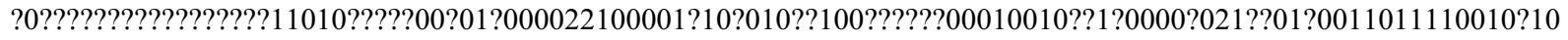
10?01???011012?111011????101?11?10?0?1?10000000???2111?1???020??11101110?0111100?0101101?0001?11011?0?000 0???00000????0????0?110011???001?0100101??????????1111??00010011110?0??0?????0??????00000????????1??1?11100?1 ?1??000?11??1?21?000000?01?010110???0?0000000000
} 


\begin{abstract}
Byronosaurus jaffei
?????101???101?1100110101011?00??????20220????????????1?100??????0000001??11????00021??01?0?0??????010110???

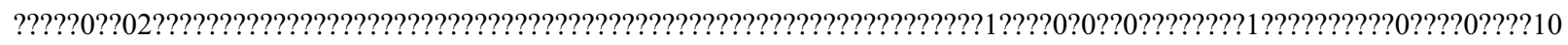
0???0?00?100?101100??0100???10?00110????????????????????????????????????????????????????????????11????????????? ???????0??11?????0??????????00000
\end{abstract}

Sinornithoides youngi

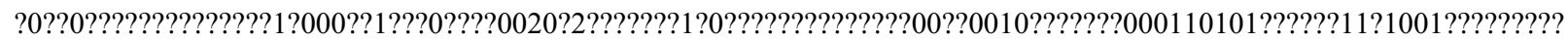

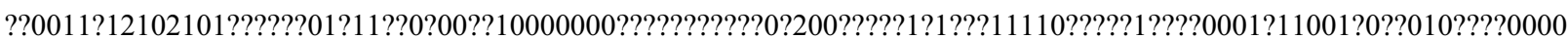
???00????30110011011??1?0100??1?000?1?0?011???0?00??01111010010100010000000000000???0???11?111110001111100 $0010 ? ? ? ? 210000000001 ? 010110 ? ? ? 0 ? 0 ? 00000000$

\begin{abstract}
Unnamed troodontid IGM100/44

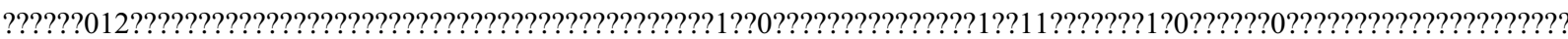

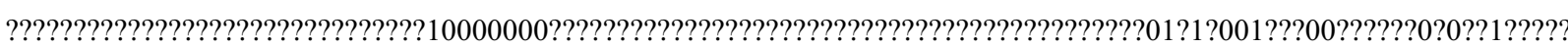

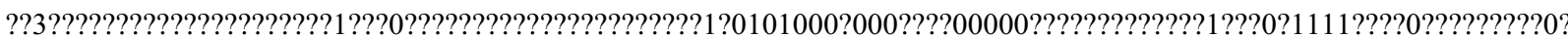
??0?????0?0?????????000?????

Troodon formosus

???1?1112?1101000001???0?010100??????20220000210?00?1?01100????0?10??001??????????011010100???1111100101101 111?1000?1020??11??????????????010????0??????????1???????????????12?0?0112100??????0100001210?019???0?0????0

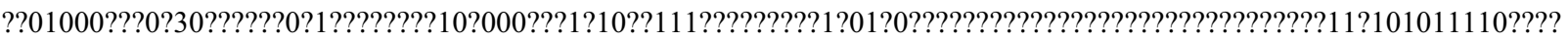
??0?101??0??000??0?????10???01??00000000
\end{abstract}

\title{
Saurornithoides mongoliensis
}

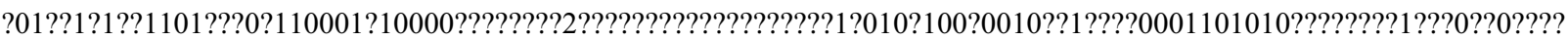

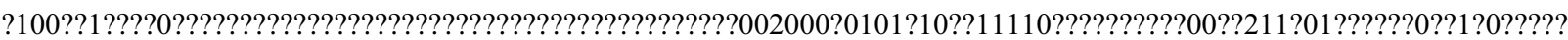
00??00?30?0001101100100000??1?0???1?010??1??0?????????????????????????????????0011??1???1??01011110????100?

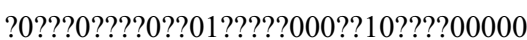

\section{Saurornithoides junior}

?01101?12?110100?001?000??100?000????2022000?21??0????11100??????100?001???1????00011010100????????????????? ?1?1000?1020???????????????????????????????????????????????????????????????????????01+????????????????00??00???1 100???0?30?1001101?001000001010000?110?0?????0??????????????????????????????????????????????1??????????????1??? ?????????0??01?1???0?0??1?????00000

\section{Unenlagia}

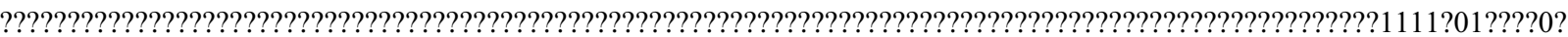
?????12????????20?0??1?01????????????0121101001110201?12??11100111110?0?????010000211?0000???????11????0???? ??0?0????????????????????????????????101??03?0??1????????????????????1?0????02119011???1?0?????211????10211021 0?000????????11????????000?????

\section{Buitreraptor gonzalezorum}

?0110???????????????0?????11?000??????????00000???0011?0?????????00??001???0??????021??10??101101110011??010?? 0100011012?121??????00101111010?1?100?0????1?11010011102??112111110??11110?00??10010000211?000?????0??1?? 00?0???000000000??1??0?0001001?0?01?0?????0?00111?00310111120??????????????????????02111011?1?1?0???2?21? ????12011021??000?0??1??1?110??0?0000?011111

\section{Austroraptor cabazai}

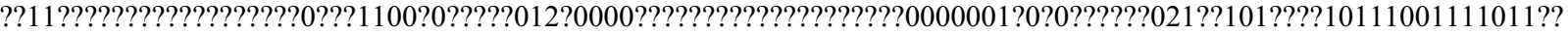

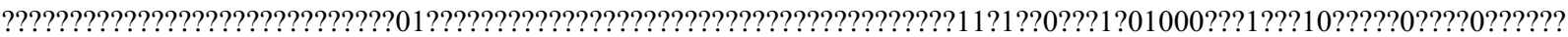

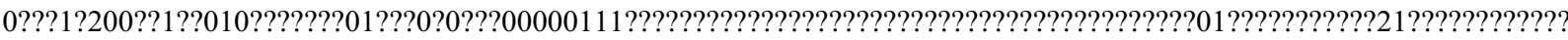
????????????????????????????11111 


\section{Rahonavis ostromi}

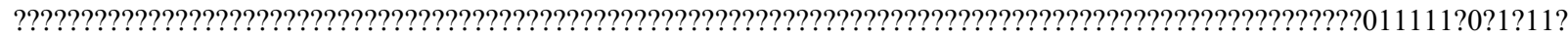

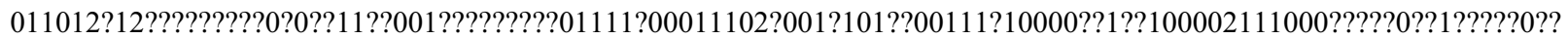

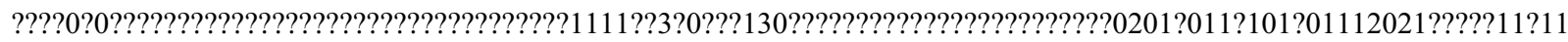
01100??01??????1?11????00?000?????

Archaeopteryx lithographica

101?0010??000??112011010??11100?011?00022100010?0000111?100111?10000000100002?0000020??[01]0100?1?0??100? 1??110?0???0021012112100?????001011110000?11000000101111?0001?102000121011101?111100000?1001000021110?00 00001001100000?0?0000102001011101000100100101?0??00?0001?11110?3?0121130110?010001000100001001020201001 $1 ? 1011011120 ? 10000010001121000000000110101 ? 0000000000000000$

\section{Wellnhoferia grandis}

?0?????????????????110?0???????????????????????????????????????00??000????????00020220010??????????????????0??

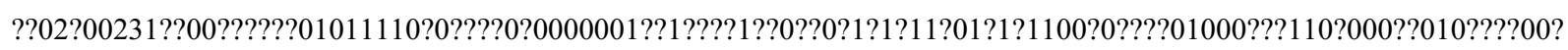
0???1000?0200101?1???????0?00????0???0?0?0??11?1?0310?21130?10?0110010001000010010202???011?1?11011120??00 $0001 ? ? 011210000000001 ? 0101 ? ? ? ? ? ? 0 ? 00000000$

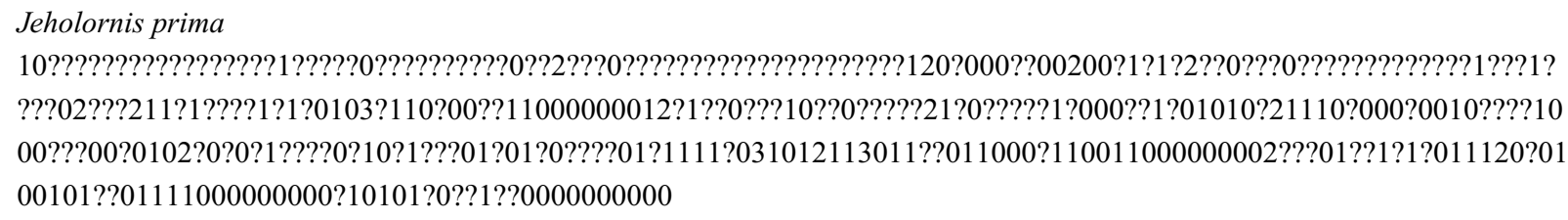

\section{Yanornis martini}

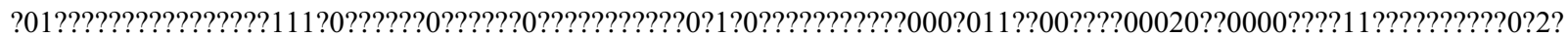

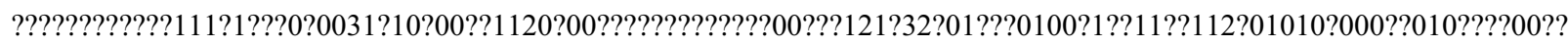

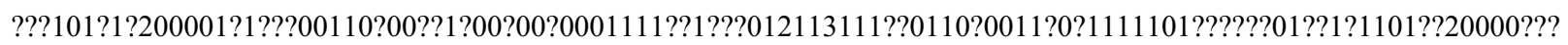
0?????1??00000000110?0??0??10???0000000?

\section{Bambiraptor feinbergi}

?0110????0?0?1??1??00?0?01110000??10?01??10?1????0?01?0????????00??010??1??0000?01011100?????0?120011??10? ?0???0011??110?????0011001011110?001?1010000010?21?001110020001?1021100?1?110000??10010001101?0?000?00?0? 1??0000????000?0000000?1013001??100101?10?011100011011000?01111201011010001000001011001010201101101?1000 01001100?001200101100000100001011110???000000000000 
Sinornithosaurus millenii

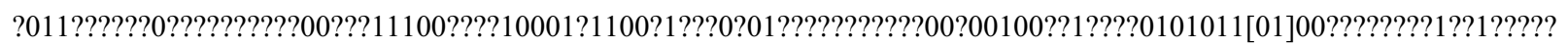

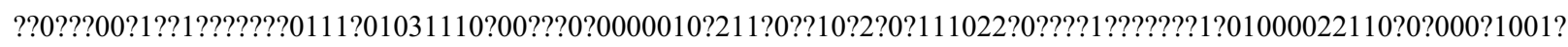
?0000???0??00?0001001101300?0?100101?1?00110?0??????00010111121?00101100001000111100001?211111??1?1000012 01?0000012??112?000001000110101?0????0??00000001

\section{Microraptor zhaoianus}

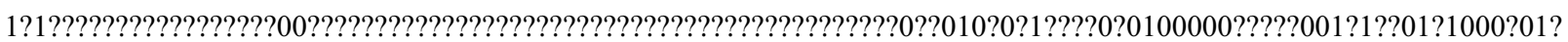
??0110?11?2111?01?100?1?1?10100?1101000011012110?011002?0?111022100?11111??00?1001?10122110??00??010?11?0 00????0??00?00?100?1?????????00??1?1?0???0??0?11110001001112110??0110000100011110010002111110?1?1000012011 $10000020 ? 11210000010001 ? 0101 ? 0 ? ? ? 000 ? 00000000$

Unnamed dromaeosaurid NGMC91

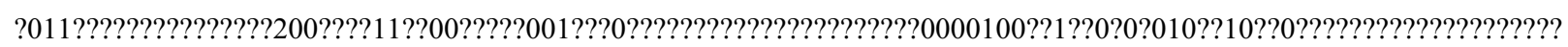

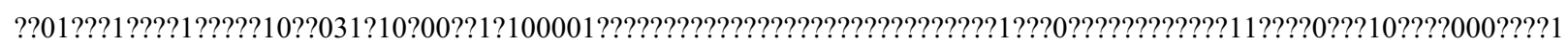
0????00010011013?01?1100??1?1?0?1?0?00?????0?0?001112110??011000?1000110100100??????1??1?1??001201110000??? ???21?0000100011010??0??????0000?????

\section{Tsaagan}

?011001001000012011200001010100001?100012110110001000??00001?0???00000100?11110001010101000????0??2?????? ?????????????????????????????????????????????????????????????????????????????????????????????????????0??00??00?0? 0000???0?0??00010013?0001000001?1???0?0?0?????????????????????????????????????????????????????????????????????? ??????????0???1?????0?????????00000

\section{Adasaurus mongoliensis}

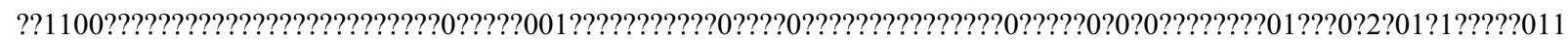

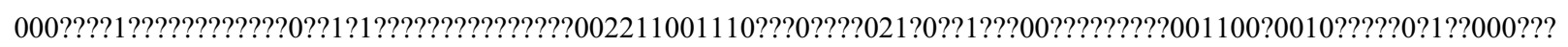

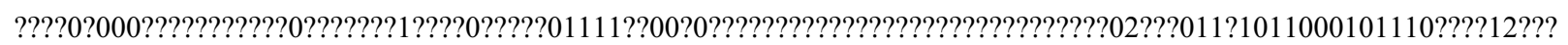
$01 ? 00 ? ? 01 ? ? ? ? ?+1 ? ? ? 0 ? ? ? ? 0 ? 0000 ? ? ? ? ?$

\section{Velociraptor mongoliensis}

?0110010010000120112000010111000011100012111?1000100010000111010100000100111100001010111000011000120011 1110111110001101110211100111001111110100111000000100221100111002000111211001111000000010010101101001000 000?001100000000000000000000100130000100000101001010000110100001001111010010100010000000110010202001011 ?001100000111000001200101100000100001010110000?000000[12]00000

\section{Saurornitholestes langstoni}

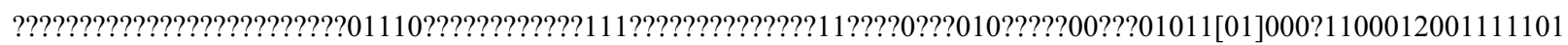

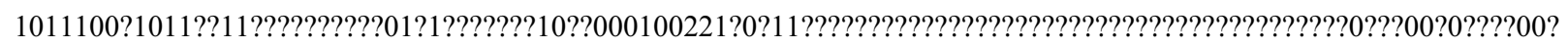

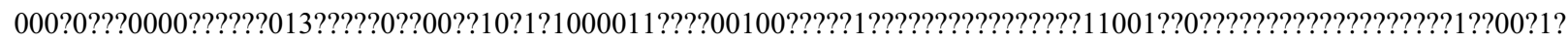
?010??0?????0??0?0?01?0???0??????????0

\section{Deinonychus antirrhopus}

?0110????1???????11?0000?0111000011100012??????0?1????0?00?11010?000?0100111?1000?010111000?1100012001?111 011????00110110?21?10???1?010111101001110000001002211001110020001110?01001111100000010010001101000000?00 ?001100000?0?000?0000??00?0013000?000????000?1?110001001??????0111101001010001000000011001020000101100011 $000101110000012 ? 0000100000100001010110000000000000000$

\footnotetext{
Achillobator giganticus

?????????????????????????01110??????????????????????????????????????????????????0001012?????0?01200?111100????? ????011??1????????0101????????????00?010220?0111100100?011010?00?11110?0????00?000?101????0???????1???0????

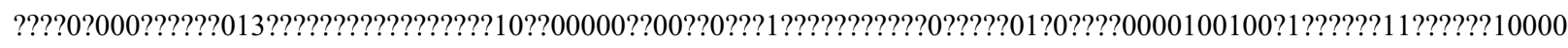
$00 ? 0 ? ? ? ? ? ? ? ? ? 0 ? ? 1 ? ? ? ? ? 0 ? ? ? 0 ? ? 00000$
} 
Dromaeosaurus albertensis

?0??001000000000010??0?0?0???0??01110????1011????10001?1001100???0000010011111000?000101000????????????????

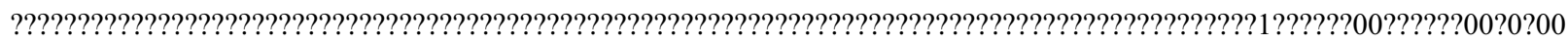
00???0?00?000?00????0??00?0010010100000?????????????????????????????????????????????????????????0111???????????

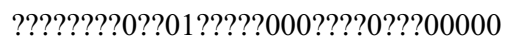

\title{
Utahraptor ostrommaysi
}

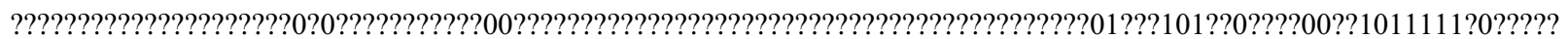

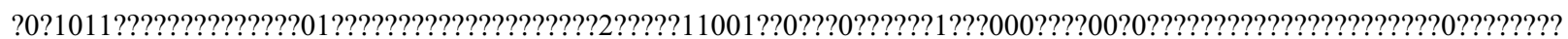
0???????0?0???????????????????0?????000??????????????????????????????????????001?00??????????????????10???0?????? ?????0?????????0??????????0

\begin{abstract}
Atrociraptor marshalli

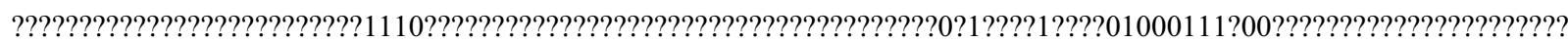

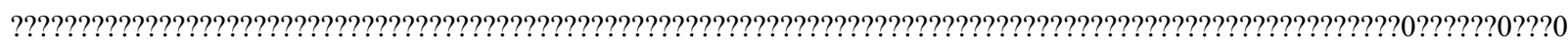
?00??00?00?3??????0?????010?0110????????????????????????????????????????????????????????????????????????????????? ???????????????????????
\end{abstract}

Epidendrosaurus ningchengensis

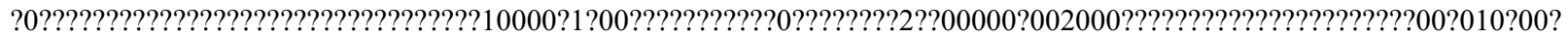

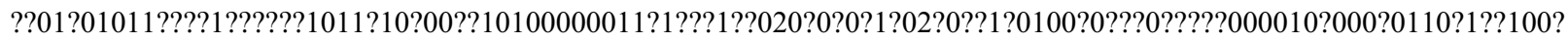

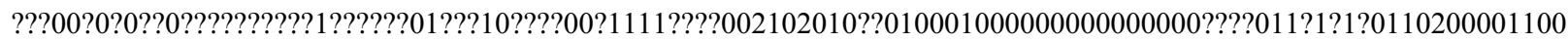
???00011000000010?11101?0??1?000111?????

\section{Epidexipteryx ningchengensis}

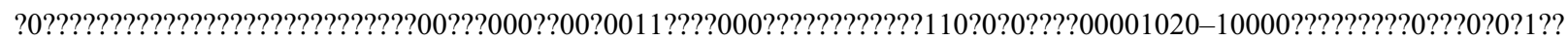

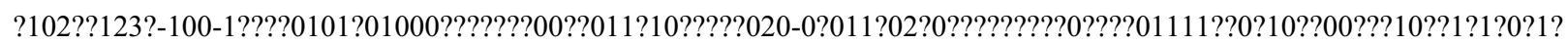

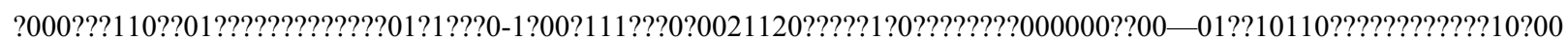
$0110 ? 000 ? 0 ? ? 1 ? 1 ? ? 11 ? ? ? 100 ? 011100000$

\section{Hagryphus giganteus}

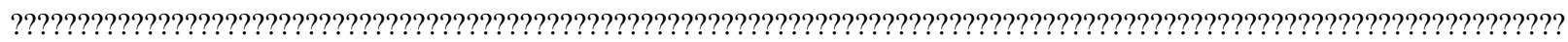

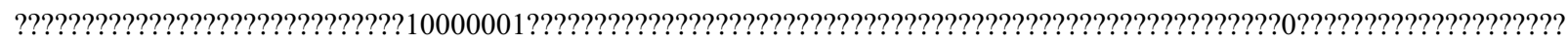
????????????????????????????????????????????????0?0111000000010001900100??????????????????????0?11,????????????? ??0??0?0????????????????

\section{Alvarezsaurus calvoi}

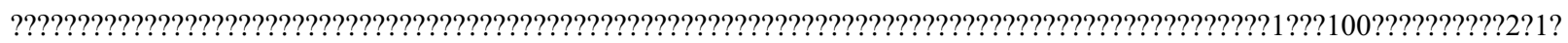

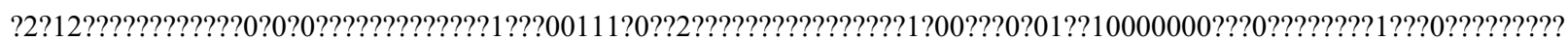

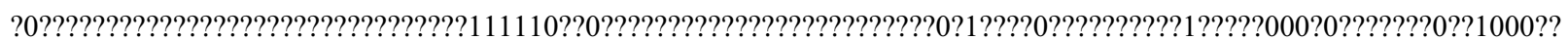
?0?????11??1????000????????

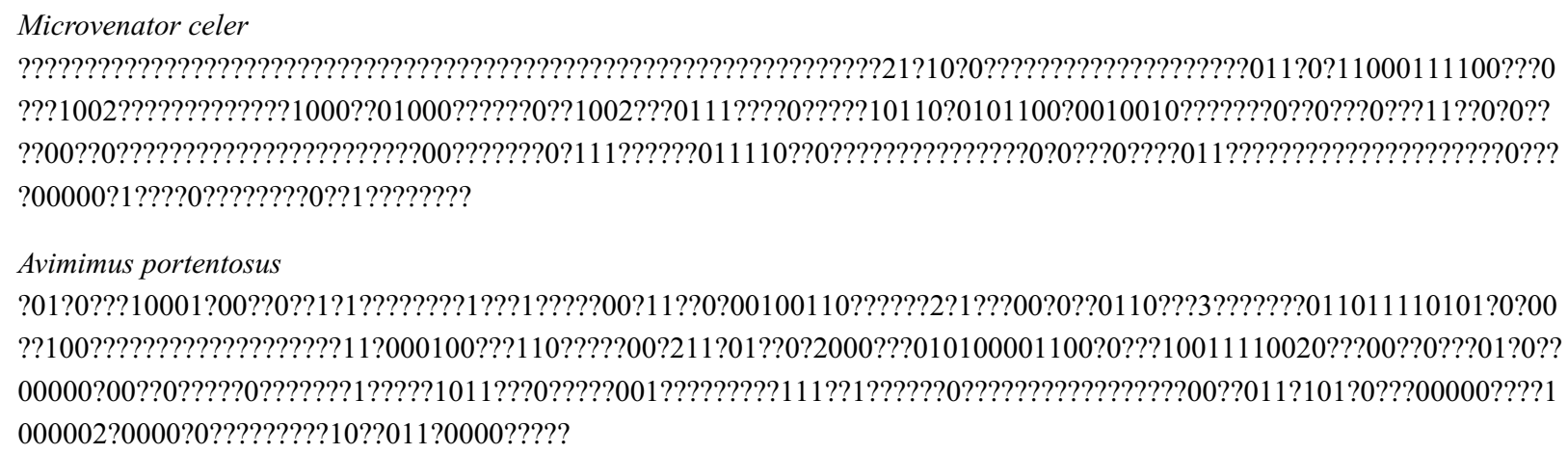




\section{Caudipteryx}

00110??????????????0?110?010000011?00013210001?00?00?????????????21010?00?????10031?3?????00????0?100??????? ?0???01????210?111000??001010001?00??1000000010020???11?02200?111?10?10?11?01??0????01000002000000000010? 110?000???0?00?0??10001001000110100111?0010?????001110?10?0001110100?01000000010?0001101?00001011?101100 0000000???010000010000000000110101?0??000010000000?

\section{Oviraptor philoceratops}

?0110?????????1??00?????111?0?011???0132??0?1?0???0?100?????1???1120?01100?01?1?1?3?????0??1???1??????1?0?? ??????????????1?????11?1?0?000001?110?0001??21,00???????????????????????????????????????????00100100?????00?

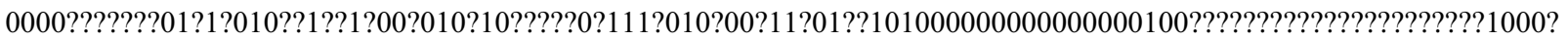

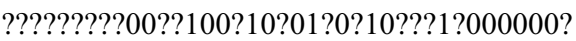

Conchoraptor gracilis

?0110??????????1???00111?1100?1011?1001321000110?000?????1?0????221120?010?0?0111?1?3???????????????010??1?0 12?110??1???0?0111???1?11?11000010????????011?00210001?102???0???01001??11010?0???20??000000??0?0???00??0110 ??0?000000??0???0101011?101001110101??????????????0?????1?1????010?0???0?00?0000111000??????1???110??????0? $0001000000 ? ? ? ? ? 0 ? ? ? 0 ? 10 ? 0 ? ? 0110101 ? 0000000 ?$

\section{Chirostenotes pergracilis}

???????01?01101??0???1?11??0???????????????????????01110????0??????????????????1???????????????1101?11????1?1 2??????????????????101?????????????000110021?000190220001110?00?0?????0?????10?100?00100000????0???1???0?0?

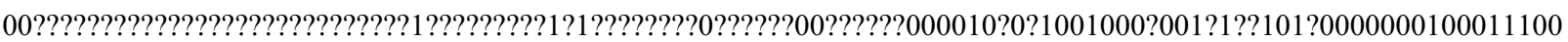
00 ?12000000??0??0???????001?????????

\section{Incisivosaurus gauthieri}

?0110???1??01?????1000101010001001?0?010??00011000?01010110101111200100001001?1?02022??0002???????????????

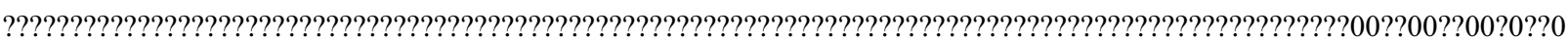
00???0010?00010?10?010010010110010??001????????????????????????????????????????????????????????????????????? ???????0??11????0110???0???0000?

Unnamed oviraptorid IGM100/42

?0110??????????????001111110?01011?100132100?11??000???01100?111221120?01100??111?1?3??????10??0??1??1?1?1?? ?1???01??00?10?1???01?1111110000?0???100000011002110?1110220??1?1010?1??1?01000????????000010000000100?001 ?0??00?0?0?00?0??101010110101001110101??10????001010010?001011?100?010001?000000000010000001011?10110??? $00000110010 ? 00010001000100 ? 10101111101011 ? ? ? ? ? ? ?$

Anchiornis huxleyi

001100????????????11010??111?00?????0?2?000??1????1?1?????????-000??01??1?????00020-01??0?101??-00?0??010?01 ???011012112?011—-011131110000??1000000010?21?1001102200?1?112112???1?1?000??1?01?001221100010?1000?1??0 0?0???0????030110?1101000100100?01?0???0-0?011111101?0001112011010100010101001110010102001011?1011000?20? $1100001000 ? 121000 ? 00000110101 ? 0 ? ? 0000000000000$

\section{APPENDIX III - Clade diagnoses for selected nodes (unambiguous synapomorphies in bold)}

Paraves: 40.2, 41.2, 123.2, 138.1, 144.1, 171.1, 176.1, 183.1, 197.1, 199.2, 201.1, 300.1, 304.2, 323.1, 333.1, 335.2.

Deinonychosauria: 62.0, 64.0, 75.1, 76.1, 95.0, 111.1, 126.1, 154.1, 198.1, 228.0, 322.1.

Troodontidae: 42.0, 72.1, 89.1, 96.1, 160.1, 232.1.

Dromaeosauridae: $20.2,36.1,40.1,43.1,71.1,82.1,84.1,107.0,120.1,125.1,240.3,253.1,330.2,342.1$. 
Avialae: 90.1, 106.1, 155.1, 159.0, 165.1, 172.2, 235.1, 270.3, 273.1, 317.1, 318.1.

Unenlagiidae: 322.2, 332.1, 369.1.

Unenlagia + (Buitreraptor + Austroraptor): 160.1, 305.1.

Buitreraptor + Austroraptor: 106.0.

Aves (=Archaeopteryx/Wellnhoferia + Ornithurae): 21.1, 116.2, 179.1, 211.1, 262.1, 274.2, 334.1.

Ornithurae: $147.1,175.2,196.1,288.0,290.1,291.1,323.0,324.1,327.1,335.1,356.1$.

\section{APPENDIX IV - Re-scored data from Hu et al. (2009) matrix}

Character numbers from the original analysis are given at left, and denoted by the letter " $\mathrm{H}$ " (Hu et al. 2009), whereas scores favoured by our current analysis are denoted by the letter "A" (present paper): Ch. 22: Buitreraptor: $\mathrm{H}=0, \mathrm{~A}=$ ?. Ch. 23: Buitreraptor: $\mathrm{H}=0, \mathrm{~A}=$ ?. Ch. 24: Buitreraptor: $\mathrm{H}=0, \mathrm{~A}=$ ?. Ch. 25: Buitreraptor: $\mathrm{H}=1, \mathrm{~A}=$ ?. Ch. 26: Buitreraptor: $\mathrm{H}=0, \mathrm{~A}=$ ?. Ch. 40: Archaeopteryx: $\mathrm{H}=0, \mathrm{~A}=2$; Jeholornis: $\mathrm{H}=$ ?, $\mathrm{A}=2$; Confusiusornis: $\mathrm{H}=$ ?, $\mathrm{A}=1$. Ch. 43: Confusiusornis: $\mathrm{H}=$ ?, $\mathrm{A}=0$; Sapeornis: $\mathrm{H}=$, $\mathrm{A}=0$; Buitreraptor: $\mathrm{H}=1, \mathrm{~A}=0 ;$ Tsaagan: $\mathrm{H}=1, \mathrm{~A}=0$; Dromaeosaurus: $\mathrm{H}=1, \mathrm{~A}=0$. Ch. 47: Buitreraptor: $\mathrm{H}=1, \mathrm{~A}=0$. Ch. 48: Buitreraptor: $\mathrm{H}=0, \mathrm{~A}=$ ?. Ch. 53: Archaeopteryx: $\mathrm{H}=$ ?, $\mathrm{A}=1$. Ch. 54: $\mathrm{H}=0$, $\mathrm{A}=1$. Ch. 55: $\mathrm{H}=$ ?, $\mathrm{A}=1$. Ch. 71: Archaeopteryx: $\mathrm{H}=1, \mathrm{~A}=0$; Wellnhoferia: $\mathrm{H}=1, \mathrm{~A}=0$; Jeholornis: $\mathrm{H}=1$, $\mathrm{A}=0$. Ch. 72: Archaeopteryyx: $\mathrm{H}=0, \mathrm{~A}=1$. Ch. 76: Buitreraptor: $\mathrm{H}=$ ?, $\mathrm{A}=0$. Ch. 85: Buitreraptor: $\mathrm{H}=1, \mathrm{~A}=0$. Ch. 88: Archaeopteryx: $\mathrm{H}=0, \mathrm{~A}=0 / 1 ;$ Saurornitholestes: $\mathrm{H}=1, \mathrm{~A}=0 / 1$. Ch. 90: Buitreraptor: $\mathrm{H}=0, \mathrm{~A}=1$; Wellnhoferia: $\mathrm{H}=2, \mathrm{~A}=1$; Archaeopteryx: $\mathrm{H}=0, \mathrm{~A}=1$. Ch. 95: Buitreraptor: $\mathrm{H}=0, \mathrm{~A}=1$. Ch. 96: Buitreraptor: $\mathrm{H}=0, \mathrm{~A}=1$. Ch. 96: Archaeopteryx: $\mathrm{H}=1, \mathrm{~A}=0$. Ch. 103: Archaeopteryx: $\mathrm{H}=0$, $\mathrm{A}=1$; Sapeornis: $\mathrm{H}=0, \mathrm{~A}=$ ?; Confusiusornis: $\mathrm{H}=$ ?, $\mathrm{A}=1$. Ch. 104: Buitreraptor: $\mathrm{H}=1, \mathrm{~A}=$; Ch. 106: Archaeopteryx: $\mathrm{H}=0, \mathrm{~A}=1$. Ch. 122: Jeholornis: $\mathrm{H}=$ ?, $\mathrm{A}=1$; Anchiornis: $\mathrm{H}=0, \mathrm{~A}=1$; Rahonavis: $\mathrm{H}=0$, $\mathrm{A}=1$; Buitreraptor: $\mathrm{H}=0, \mathrm{~A}=1$; Unenlagia: $\mathrm{H}=0, \mathrm{~A}=1$. Ch. 123: Anchiornis: $\mathrm{H}=$ ?, $\mathrm{A}=2$; Archaeopteryx: $\mathrm{H}=1, \mathrm{~A}=2$. Ch. 133: Buitreraptor: $\mathrm{H}=1, \mathrm{~A}=0$. Ch. 144: Rahonavis: $\mathrm{H}=0, \mathrm{~A}=1$. Ch. 155: Buitreraptor: $\mathrm{H}=$ ?, $\mathrm{A}=1$. Ch. 157: Archaeopteryx: $\mathrm{H}=2, \mathrm{~A}=1$; Confusiusornis: $\mathrm{H}=2, \mathrm{~A}=1 ;$ Unenlagia: $\mathrm{H}=2, \mathrm{~A}=1$; Rahonavis: $\mathrm{H}=2, \mathrm{~A}=1$; Jeholornis: $\mathrm{H}=2, \mathrm{~A}=$ ?. Ch. 159: Buitreraptor: $\mathrm{H}=1, \mathrm{~A}=0$; Unenlagia: $\mathrm{H}=$, $\mathrm{A}=1$. Ch. 162: Unenlagia: $\mathrm{H}=$ ?, $\mathrm{A}=0$; Buitreraptor: $\mathrm{H}=1, \mathrm{~A}=0 ;$ Rahonavis: $\mathrm{H}=1, \mathrm{~A}=0$. Ch. 163: Buitreraptor: $\mathrm{H}=$ ?, $\mathrm{A}=1$. Ch. 164: Buitreraptor: $\mathrm{H}=$ ?, $\mathrm{A}=1$. Ch. 165: Archaeopteryx: $\mathrm{H}=0, \mathrm{~A}=1$. Ch. 166: Buitreraptor: $\mathrm{H}=2, \mathrm{~A}=0$. Ch. 170: Unenlagia: $\mathrm{H}=0, \mathrm{~A}=$ ?. Ch. 171: Buitreraptor: $\mathrm{H}=$, $\mathrm{A}=1$. Ch. 172: Unenlagia: $\mathrm{H}=$ ?, $\mathrm{A}=2$; Buitreraptor: $\mathrm{H}=1, \mathrm{~A}=2$. Ch. 175: Buitreraptor: $\mathrm{H}=$ ?, $\mathrm{A}=1$. Ch. 178: Unenlagia: $\mathrm{H}=2, \mathrm{~A}=0$. Ch. 181: Buitreraptor: $\mathrm{H}=$ ?, $\mathrm{A}=1$. Ch. 183: Wellnhoferia: $\mathrm{H}=0$, $\mathrm{A}=1$; Unenlagia: $\mathrm{H}=0, \mathrm{~A}=1$. Ch. 184: Buitreraptor: $\mathrm{H}=$ ?, $\mathrm{A}=1$. Ch. 185: Unenlagia: : $\mathrm{H}=$ ?, $\mathrm{A}=0$. Ch. 187: Buitreraptor: $\mathrm{H}=$ ?, $\mathrm{A}=0$. Ch. 192: Buitreraptor: $\mathrm{H}=$ ?, $\mathrm{A}=0$. Ch. 195: Buitreraptor: $\mathrm{H}=1$, $\mathrm{A}=0$. Ch. 197: Buitreraptor: $\mathrm{H}=$ ?, $\mathrm{A}=0$; Archaeopteryx: $\mathrm{H}=1, \mathrm{~A}=0$; Wellnhoferia: $\mathrm{H}=1, \mathrm{~A}=0$; Jeholornis: $\mathrm{H}=1, \mathrm{~A}=0$. Ch. 198: Sinornithosaurus: $\mathrm{H}=1, \mathrm{~A}=0$; Anchiornis: $\mathrm{H}=0, \mathrm{~A}=1 ;$ Buitreraptor: $\mathrm{H}=1, \mathrm{~A}=0$; Rahonavis: $\mathrm{H}=1, \mathrm{~A}=0$. Ch. 199: Sinornithosaurus: $\mathrm{H}=1, \mathrm{~A}=2$; Anchiornis: $\mathrm{H}=1, \mathrm{~A}=2$; Rahonavis: $\mathrm{H}=1$, $\mathrm{A}=2$; Buitreraptor: $\mathrm{H}=1, \mathrm{~A}=2$; Microraptor: $\mathrm{H}=1, \mathrm{~A}=2$; Archaeopteryx: $\mathrm{H}=$ ?, $\mathrm{A}=2$; Jeholornis: $\mathrm{H}=$, $\mathrm{A}=2$. Ch. 200: Archaeopteryx: $\mathrm{H}=0, \mathrm{~A}=1$; Anchiornis: $\mathrm{H}=0, \mathrm{~A}=1$; Protopteryx: $\mathrm{H}=0, \mathrm{~A}=1$; Jeholornis: 
$\mathrm{H}=0, \mathrm{~A}=1$; Sapeornis: $\mathrm{H}=0, \mathrm{~A}=1$; Confusiusornis: $\mathrm{H}=0, \mathrm{~A}=1$; Yanornis: $\mathrm{H}=0, \mathrm{~A}=1$; Buitreraptor: $\mathrm{H}=2$, $\mathrm{A}=1$; Rahonavis: $\mathrm{H}=2, \mathrm{~A}=1$. Ch. 201: Jeholornis: $\mathrm{H}=0, \mathrm{~A}=1$; Wellnhoferia: $\mathrm{H}=0, \mathrm{~A}=1$; Archaeopteryx: $\mathrm{H}=0, \mathrm{~A}=1$. Ch. 202: Unenlagia: $\mathrm{H}=0, \mathrm{~A}=$ ?; Buitreraptor: $\mathrm{H}=0, \mathrm{~A}=$ ?; Rahonavis: $\mathrm{H}=0, \mathrm{~A}=1$. Ch. 220: Unenlagia: $\mathrm{H}=$ ?, $\mathrm{A}=0$. Ch. 230: Buitreraptor: $\mathrm{H}=$ ?, $\mathrm{A}=0$. Ch. 231: Buitreraptor: $\mathrm{H}=$ ?, $\mathrm{A}=0$. Ch. 235: Buitreraptor: $\mathrm{H}=$ ?, $\mathrm{A}=1$. Ch. 240: Buitreraptor: $\mathrm{H}=0, \mathrm{~A}=1$. Ch. 228: Buitreraptor: $\mathrm{H}=$ ?, $\mathrm{A}=0$. Ch. 270: Unenlagia: $\mathrm{H}=$ ?, $\mathrm{A}=3$; Buitreraptor: $\mathrm{H}=$ ?, $\mathrm{A}=3$. Ch. 273: Bambiraptor: $\mathrm{H}=0, \mathrm{~A}=1$; Buitreraptor: $\mathrm{H}=0$, $\mathrm{A}=1$; Sinornithosaurus: $\mathrm{H}=0, \mathrm{~A}=1$. Ch. 274: Unenlagia: $\mathrm{H}=1, \mathrm{~A}=$ ?. Ch. 304: Buitreraptor: $\mathrm{H}=$, $\mathrm{A}=2$. Ch. 305: Rahonavis: $\mathrm{H}=1, \mathrm{~A}=0$. Ch. 306: Buitreraptor: $\mathrm{H}=$ ?, $\mathrm{A}=1$; Unenlagia: $\mathrm{H}=0, \mathrm{~A}=1$. Ch. 308: Buitreraptor: $\mathrm{H}=$ ?, $\mathrm{A}=0$. Ch. 312: Buitreraptor: $\mathrm{H}=$ ?, $\mathrm{A}=1$. Ch. 315: Rahonavis: $\mathrm{H}=0, \mathrm{~A}=$; Buitreraptor: $\mathrm{H}=0, \mathrm{~A}=$ ?. Ch. 318: Rahonavis: $\mathrm{H}=$ ?, $\mathrm{A}=1$. Ch. 320: Buitreraptor: $\mathrm{H}=0, \mathrm{~A}=2$; Rahonavis: $\mathrm{H}=0, \mathrm{~A}=2$. Ch. 322: Archaeopteryx: $\mathrm{H}=0, \mathrm{~A}=$ ?; Wellnhoferia: $\mathrm{H}=0, \mathrm{~A}=$ ?; Jaeholornis: $\mathrm{H}=0, \mathrm{~A}=$. Ch. 330: Unenlagia: $\mathrm{H}=2, \mathrm{~A}=0$. Ch. 333: Jeholornis: $\mathrm{H}=$ ?, $\mathrm{A}=1$; Archaeopteryx: $\mathrm{H}=0, \mathrm{~A}=1$. Ch. 334: Rahonavis: $\mathrm{H}=$ ?, $\mathrm{A}=0$. 